\title{
Objective Analysis of SMOS and SMAP Sea Surface Salinity to Reduce Large-Scale and Time-Dependent Biases from Low to High Latitudes 0
}

\author{
Nicolas KolodziejczyK, ${ }^{a}$ Mathieu Hamon, ${ }^{a}$ Jacqueline Boutin, ${ }^{\mathrm{b}}$ JeAn-Luc Vergely, \\ Gilles Reverdin, ${ }^{\mathrm{b}}$ Alexandre Supply, ${ }^{\mathrm{b}}$ AND NicOlas Reul ${ }^{\mathrm{a}}$ \\ ${ }^{a}$ University of Brest, LOPS Laboratory, IUEM, UBO-CNRS-IRD-Ifremer, Plouzané, France \\ ${ }^{\mathrm{b}}$ Sorbonne University, LOCEAN Laboratory, CNRS-IRD-MNHM, Paris, France \\ ${ }^{\mathrm{c}}$ ACRI-ST, Guyancourt, France
}

(Manuscript received 25 June 2020, in final form 13 October 2020)

\begin{abstract}
Ten years of L-band radiometric measurements have proven the capability of satellite sea surface salinity (SSS) to resolve large-scale-to-mesoscale SSS features in tropical to subtropical ocean. In mid-to-high latitudes, L-band measurements still suffer from large-scale and time-varying errors. Here, a simple method is proposed to mitigate the large-scale and time-varying errors. First, an optimal interpolation using a large correlation scale $(\sim 500 \mathrm{~km})$ is used to map independently Soil Moisture Ocean Salinity (SMOS) and Soil Moisture Active Passive (SMAP) level-3 (L3) data. The mapping is compared with the equivalent mapping of in situ observations to estimate the large-scale and seasonal biases. A second mapping is performed on adjusted SSS at the scale of SMOS/SMAP spatial resolution $(\sim 45 \mathrm{~km})$. This procedure merges both products and increases the signal-to-noise ratio of the absolute SSS estimates, reducing the root-mean-square difference of in situ satellite products by about $26 \%-32 \%$ from mid- to high latitudes, respectively, in comparison with the existing SMOS and SMAP L3 products. However, in the Arctic Ocean, some issues on satellite retrieved SSS related to, for example, radio frequency interferences, land-sea contamination, and ice-sea contamination remain challenging to reduce given the low sensitivity of L-band radiometric measurements to SSS in cold water. Using the International Thermodynamic Equation Of Seawater-2010 (TEOS-10), the resulting level-4 SSS satellite product is combined with satellite-microwave SST products to estimate sea surface density, spiciness, and haline contraction and thermal expansion coefficients. For the first time, we illustrate how useful these satellite-derived parameters are to fully characterize the surface ocean water masses at large mesoscale.
\end{abstract}

KEYWORDS: Ocean; Salinity; In situ oceanic observations; Satellite observations; Surface observations; Interpolation schemes

\section{Introduction}

Salinity is an essential ocean and climate variable. Along with temperature, it plays a fundamental role in the thermohaline global circulation and climate variability. Ocean salinity is also a key parameter for monitoring the global water cycle. The ocean salinity and temperature contribute together to the ocean water mass characteristics. These characteristics include density, a key parameter controlling the ocean stability and the ocean current dynamic; and the spiciness that is the isopycnal density-compensated contrasts of temperature and salinity: a passive tracer for water masses (McDougall and Krysik 2015). It is also worth noticing that stratification and density gradients largely depend on salinity in the subpolar and high latitudes where the temperature is getting colder (Carmack 2007). This results from a reduced (increased) thermal expansion (haline contraction coefficient), but also from relatively larger salinity contrasts and more homogeneous temperature in cold regions. In addition, strong freshwater input from high rain rate, river

Supplemental information related to this paper is available at the Journals Online website: https://doi.org/10.1175/JTECH-D-200093.s1.

Corresponding author: Nicolas Kolodziejczyk, nicolas.kolodziejczyk@ univ-brest.fr discharge or sea ice melt can produce strong stratification in the upper layer inhibiting the vertical mixing of heat, momentum and nutrients (Lukas and Lindstrom 1991; Dewey et al. 2017). At high latitudes, the presence of a sharp halocline prevents heat stored in the deeper ocean layers to reach the surface and melt the sea ice (Carmack 2007; Lique 2015). In the tropics, salinity stratification, by modulating air-sea exchange, can have a strong impact on El Niño-Southern Oscillation (ENSO; Vialard and Delecluse 1998), on Indian monsoon precipitation (Shenoi and Shankar 2002), or on the oceanic productivity (Picaut et al. 2001). Eventually, in the context of anthropogenic climate change, the ocean salinity is also a key indicator of climate changes, since it is a tracer of the hydrological cycle (Durack et al. 2012).

Ten years of L-band satellite measurements produced by the Soil Moisture Ocean Salinity (SMOS) European mission (2010-present; Kerr et al. 2010; Font et al. 2010), the Aquarius (2011-15) (Lagerloef et al. 2008) and Soil Moisture Active Passive NASA (SMAP) missions (2015-present) (Piepmeier et al. 2017) have proven the capability to measure sea surface salinity (SSS) from space and provide the longest multisensor satellite SSS time series ever recorded (Vinogradova et al. 2019; Reul et al. 2020).

L-band radiometry has stimulated studies on ocean near surface salinity in tropical and subtropical regions: describing SSS change associated with ENSO events (Hasson et al. 2014, 2018) and Indian Ocean dipole (Durand et al. 2013), and 
subtropical SSS maxima in the North Atlantic and South Pacific Oceans, including studies of mesoscale and frontal variability that have been made possible for the first time from SMOS and SMAP satellite SSS (e.g., Reul et al. 2014b; Kolodziejczyk et al. 2015a; Sommer et al. 2015; Hasson et al. 2019). In addition, using satellite SSS in the assimilation system significantly improves the ENSO forecasts (Hackert et al. 2020). Important patterns associated with the freshwater flux entering the ocean, such as in river plumes, have also been better documented from SMOS (Reul et al. 2014a; Fournier et al. 2015) and SMAP SSS (Fournier et al. 2017), as the filtering and correction of L-band measurements near the coast have been progressively improved (Meissner et al. 2018; Kolodziejczyk et al. 2016; Boutin et al. 2018a).

At higher latitudes than $45^{\circ} \mathrm{N} / \mathrm{S}$, SSS retrievals from L-band radiometry have been subject to larger errors with the presence of large-scale $(\sim 500 \mathrm{~km})$ and seasonal-dependent systematic errors. First, anthropic radio frequency interferences (RFIs) strongly contaminate the high northern latitudes until 2012-13. After this date, they have been turned off in the northern high latitudes by emitting countries. Second, the sensitivity of L-band radiometric data to SSS gets lower with decreasing SST, hence the signal-to-noise ratio for individual retrievals decreases (Tang et al. 2018; Olmedo et al. 2018; Xie et al. 2019). Furthermore, at high latitudes, SSS retrievals are more sensitive to errors in radiative transfer model components, e.g., uncertainties in sea surface roughness corrections, dielectric constant parameterization, high and variable wind speed more common at high latitude. The seasonal and interannual variability of the sea ice edge hinders the methodology used for coastal systematic error correction (Kolodziejczyk et al. 2016). There is also a challenging issue of filtering the icecontaminated brightness temperature in the marginal ice zone that results in larger errors in partially ice covered regions at high latitudes (Supply et al. 2020).

In this study, we present a simple method for correcting large-scale and time-varying errors; however, the ice edge and RFIs contamination cannot be fully addressed because of the small scale of such artifacts. Using objective analysis mapping, the large-scale (on the order of $500 \mathrm{~km}$ ) and time-varying ( $\sim 30$ days) errors from the SMOS and SMAP level-3 data (hereinafter SMOS L3 and SMAP L3, respectively) products are estimated by comparison with monthly large-scale mapping of in situ observations (Gaillard et al. 2016), mainly from Argo data (Roemmeich et al. 2019). This approach using systematic satellite measurements calibration from in situ data was inspired from correction methodology implemented for the mapping of infrared satellite SST, contaminated by largescale aerosol and dust clouds from volcano eruptions in the 1980s (Reynolds and Smith 1994). Then, mapping at higher spatial resolution of the satellite measurements (at the moderate resolution of the satellite data, i.e., $\sim 45 \mathrm{~km}$ ) is performed to retrieve smaller scales of the variability. The resulting OI level-4 SSS (hereinafter OI L4 SSS) fields can then be merged with satellite SST products in order to compute density, spiciness and other thermodynamic parameters from International Thermodynamic Equation Of Seawater-2010 (TEOS-10) equation (IOC, SCOR, and IAPSO 2010). In the next section, we present the data used. Then the bias correction and mapping methodologies are described. We also discuss the validation of the new OI L4 SSS products.

\section{Data}

\section{a. Input to level-4 OI SSS}

\section{1) SMOS L3 DATA}

The SMOS SSS are available since January 2010 (Fig. 1). The SMOS satellite mission is still operating. It is equipped with the Microwave Imaging Radiometer Using Aperture Synthesis (MIRAS) instrument, which is a two-dimensional interferometric passive radiometer operated at L-band frequency $(1.4 \mathrm{GHz})$. This synthetic aperture antenna technology provides an average ground spatial resolution on the order of $45 \mathrm{~km}$ (between 35 and $100 \mathrm{~km}$ ). The SMOS satellite is on a sun-synchronous circular orbit with a local equator-crossing time at 0600 LT on the ascending node with a revisit time of 35 days (see Boutin et al. 2018a).

The SMOS L3 maps used in this study are the 9-day debias version 3 maps produced by the Laboratoire d'Océanographie et du Climat: Expérimentations et Approches Numériques (LOCEAN) Expertise Center (CEC) of Centre Aval de Traitement des Données SMOS (CATDS) (Boutin et al. 2018b) and mapped on an ESA Equal-Area Scalable Earth (EASE) horizontal grid with a resolution of $25 \times 25 \mathrm{~km}^{2}$. These SMOS L3 maps result from a successive filtering and smoothing with a 9-days Gaussian window of the level-2 retrieved SSS using a Bayesian approach. They are corrected from systematic land-sea contamination, across-swath SSS systematic errors and seasonal latitudinal systematic errors using SMOS SSS self-consistency criteria (Kolodziejczyk et al. 2016). The long term SSS absolute calibration is derived from the $80 \%$ upper quantile of the In Situ Analyses System (ISAS; in situ data climatology) 6-yr SSS statistical distribution, but the temporal variability of these SMOS L3 SSS is independent of in situ SSS (Boutin et al. 2018a). The SMOS L3 maps since 2011 are used in this study (Fig. 1).

\section{2) SMAP L3 DATA}

The SMAP satellite was launched on 31 January 2015 and provides SSS observations since April 2015 from a passive L-band radiometer initially designed to measure soil moisture from space (Fig. 1). The SMAP radiometer allows a ground resolution on the order of $40 \mathrm{~km}$. The SMAP satellite is in a sun-synchronous near-polar orbit at an inclination of $98^{\circ}$ and an altitude of $685 \mathrm{~km}$, with an ascending node time of $1800 \mathrm{LT}$. It completes global coverage in approximately 3 days, with an exact repeat cycle of 8 days (Meissner et al. 2016).

We use the SMAP level-3 v3 8-day 40-km products provided by Remote Sensing Systems (RSS) and retrieved directly from the geophysical model (Meissner et al. 2018). Over the open ocean, the v3.0 release reduces spurious temporal and zonal biases using the Scripps Argo optimal interpolation (OI) product (Meissner et al. 2018). The major change of v4.0 from v3.0 is an improved sidelobe correction near coast and ice mask switched from NCEP to AMSR-2, respectively (Meissner et al. 2019). 


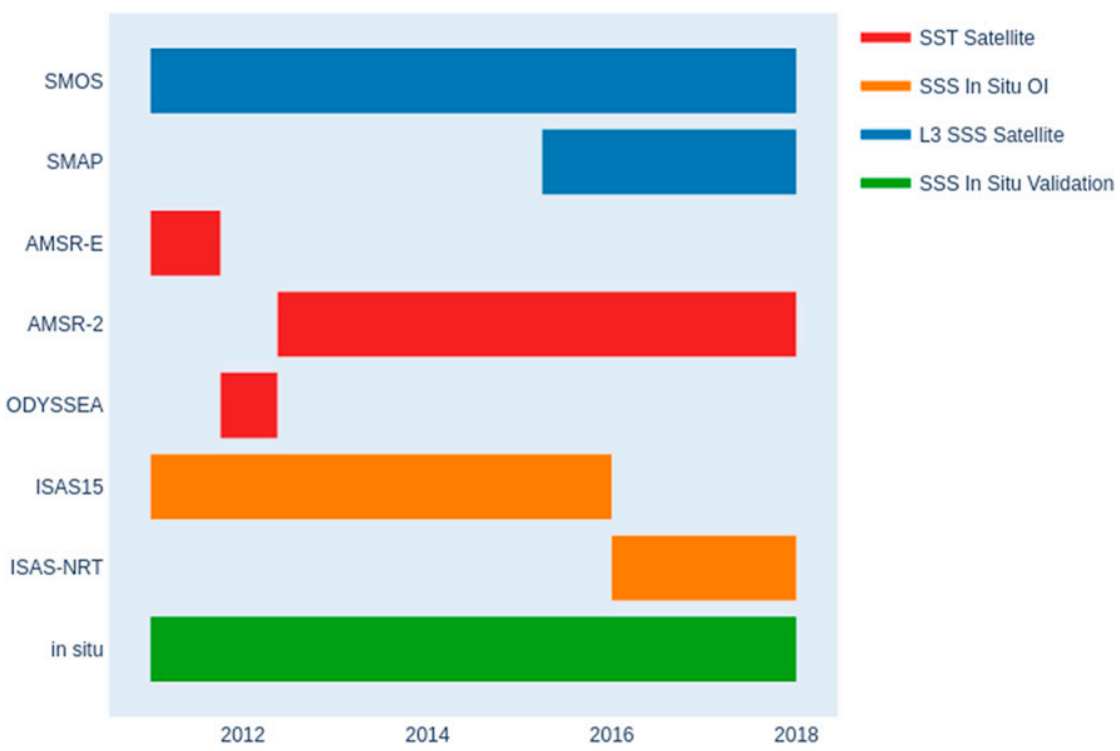

FIG. 1. Gantt diagram of temporal coverage of each dataset used in the generation of the suite of products OI L4 SSS between 2011 and 2017: the SMOS L3 v3 and SMAP L3 v3 (blue) objectively analyzed; ISAS-15 and ISAS-NRT in situ SSS objective analyses used to calibrate the L3 SSS satellite products (orange); SST satellite products used to combine with the OI L4 SSS to produce density, spiciness, and thermal expansion and haline contraction coefficients (red); and availability of in situ SSS validation dataset (green).

In our study, we applied our own land mask to get rid of land contamination near the coasts. Therefore, the $\mathrm{v} 4.0$ release was not considered.

\section{3) ISAS PRODUCTS}

The ISAS provides interpolated fields from in situ SSS. Monthly gridded fields of salinity derived from in situ measurements are obtained using an optimal interpolation (OI) (Bretherton et al. 1976) tool developed for the synthesis of the Argo global dataset (Gaillard et al. 2016). The interpolation is mainly based on delayed mode Argo floats temperature and salinity measurements. Since 2000s, the international Argo program has deployed a global array of autonomous floats that provides quality-controlled profiles every 10 days with a quasihomogeneous global coverage of $3^{\circ} \times 3^{\circ}$ over the first $2000-\mathrm{m}$ depth (Roemmeich et al. 2019). Other quality-controlled datasets are interpolated with ISAS tool: the Global Tropical Moored Buoy Array (https://www.pmel.noaa.gov/gtmba/) temperature and salinity time series, and conductivitytemperature-depth (CTD) from marine mammals equipped by French Observing System-Mammals as Samplers of the Ocean Environment (SO-MEMO) in the framework of Marine Mammals Exploring Ocean Pole to Pole (www.meop.net/ groups/france.html).

We use the ISAS fields reconstructed at 5-m depth on a halfdegree horizontal grid. Over the 2011-15 period (Fig. 1), ISAS15 (Kolodziejczyk et al. 2017) fields have been produced after a refined quality check of the Argo profiles. Data are preprocessed for ISAS-15 using a climatological test and followed by a visual control of suspicious profiles. The ISAS NearReal Time (ISAS-NRT) monthly fields are produced by Coriolis data center in the framework of Copernicus In Situ Thematic Assembly Center (www.coriolis.eu.org/Data-Products/DataDelivery/Copernicus-In-Situ-TAC). ISAS-NRT fields are used to extend the ISAS-15 time series since 2016 (Fig. 1).

\section{b. Microwave SST fields}

To compute density, spiciness, thermal expansion and haline contraction, SST products have been combined with OI L4 SSS data. For this purpose, we should use SST products with a similar resolution. Therefore, the AMSR-E/2 microwave satellite SST products, with a spatial resolution on the order of $0.25^{\circ} \times 0.25^{\circ}$, have been used. AMSR-E was launched on the NASA's EOS Aqua spacecraft, on 4 May 2002 until 4 October 2011. AMSR-2 was launched on the JAXA's Global Change Observation Mission for Water 1 (GCOM-W1) spacecraft, on 18 May 2012 and is still operating (Fig. 1).

AMSR-E/2 SST products are provided by RSS (Wentz et al. 2014). The AMSR series of instruments are passive microwave radiometers placed in a near-polar orbit that allows for up to twice-daily sampling of a given Earth location. The AMSR instrument has eight microwave channels for measuring SST, wind speed, cloud liquid water, water vapor content and rain rate. The SST products used in this study is the weekly product binned on a $0.25^{\circ}$-resolution grid, which spans the period from 18 May 2012 until now (Wentz et al. 2014). We have compared the satellite SST with high resolution SST from ship thermosalinograph transect using a coherency spectra approach in the subtropical and tropical Atlantic domain (section S1 in the online supplemental material). As found from comparisons in these regions, the satellite SST is able to resolve wavelengths larger than $200 \mathrm{~km}$. This is comparable to 
wavelengths resolved by the nominal satellite SSS resolution of $45 \mathrm{~km}$ ( $\sim$ wavelength $200 \mathrm{~km}$; Fig. S1 in the online supplemental material).

Between 4 October 2011 and 18 May 2012, AMSR-E/2 products were not available, and the ODYSSEA-NRT products was used to fill the 8-month SST data gap (Fig. 1). ODYSSEA is a merged microwave-infrared L4 SST product provided by the Ifremer Centre ERS d'Archivage et de Traitement (CERSAT) (http://products.cersat.fr/). ODYSSEA SST fields are distributed every $24 \mathrm{~h}$ on a $0.1^{\circ} \times 0.1^{\circ}$ grid (approximately $10 \mathrm{~km} \times 10 \mathrm{~km}$ ) for the global ocean. FOI techniques are used to combine coincident swath SST measurements from different sensors and to fill gaps where no observations are available. Whereas swath data essentially represent the skin or subskin SST, the L4 SST product is an estimated SST foundation (SSTfnd). SSTfnd is never directly observed by satellites, but it is close to what is detected by a microwave radiometer that penetrates the skin, at dawn, when the previous day's diurnal stratification can be assumed to have decayed and SSTsubskin, SSTdepth and SSTfnd are very close [see Autret et al. (2019) for more details].

\section{c. Validation dataset}

Near surface in situ salinity and temperature observations are provided by thermosalinographs (TSG) installed on voluntary merchant ships (Alory et al. 2015). They provide solid SSS estimates representative of the upper $10 \mathrm{~m}$ with an $\sim 2.5$-km horizontal resolution along the ship track. TSG data are independent from ISAS maps since they are not interpolated along with other in situ datasets in ISAS fields, except in the ISAS-NRT. However, correlations scales used in ISAS-NRT smooth out the small and mesoscale features from TSG measurements, thus the independent validation of these scales remain possible. Noise on individual ship SSS data is estimated to be on the order of 0.08 on Practical Salinity Scale of 1978 (hereinafter pss) (Alory et al. 2015). These TSG dataset samples mostly the low to midlatitudes, up to $60^{\circ} \mathrm{N}-\mathrm{S}$ (Fig. 1 ).

To obtain in situ sampling at higher latitudes, additional data from the research vessels R/V Heincke, the R/V Polarstern, the R/V Mirai and the S/V Tara are integrated in the dataset (Supply et al. 2020). Data from R/V Heincke and R/V Polarstern are downloaded PANGAEA (https://www.pangaea.de). R/V Mirai data are downloaded from the Data and Sample Research System for Whole Cruise Information (DARWIN) website of JAMSTEC (http://www.godac.jamstec.go.jp/darwin/e). The S/V Tara measurements are provided by Reynaud et al. (2015). The TSG measurements from these vessels are carried out at different depths from $1 \mathrm{~m}$ for S/V Tara to $11 \mathrm{~m}$ for R/V Polarstern. In this study, only TSG measurements taken at shallower depth than $5 \mathrm{~m}$ are considered.

At high latitudes, in particular in the Nordic seas, salinity and temperature measurements from Argo profiling floats are used to enhance the validation database. They are provided by the Coriolis Global Data Assembly Center (GDAC) (Argo data, 2019). The measurements are filtered as follows: measurements flagged (flag 1) as good are retained and at a depth shallower than $10 \mathrm{~m}$ are used, if flagged good. Note that when the Argo CTD pump is turned off above 5-m depth the data are usually flagged as bad.

In the Arctic seas, most of the CTD profiles used were downloaded from the Coriolis data center. Additional CTD profiles are integrated to the validation dataset. This includes CTD casts from two Nansen and Amundsen Basins Observational System (NABOS) cruises (see NABOS 2013 and 2015 reports) in the Kara, Laptev, and East Siberian Seas, data from the Arctic Floating University (Makhotin and Ivanov 2018) in the Barents Sea, CTD profiles in the Laptev and East Siberian Seas collected during Swerus C-3 cruise (Björk 2017), and Woods Hole CTD casts from the Beaufort Sea provided by the Beaufort Gyre Exploration Project website (https://www.whoi.edu/website/beaufortgyre/home). Only measurements shallower than 10-m depth are considered.

Given the depth of in situ salinity "surface" measurements (between 1- and 10-m depth), surface salinity stratification is a key issue for calibration and validation of skin satellite SSS. The major biases are observed in regions of river plumes and ice melting (Supply et al. 2020). Therefore, the comparison with in situ measurements should include a "representativeness error" that is dependent on salinity stratification in the upper layer of the ocean, but also on the small scales observed within the footprint of the satellite $(<45 \mathrm{~km})$ (Boutin et al. 2016). Typically, in stratified Arctic regions, Supply et al. (2020) estimate differences between SMOS SSS and in situ salinity at $5 \mathrm{~m}$ up to $1.5 \mathrm{pss}$. Concerning the horizontal representativeness error, Boutin et al. (2016) estimate the SSS variance in $1^{\circ} \times 1^{\circ}$ squares large than 0.5 pss in intense dynamical regions such as western boundary currents and freshwater plumes.

\section{Method}

\section{a. Objective analysis}

OI of satellite L3 SSS data is performed following Bretherton et al. (1976), presented here in the formalism of Ide et al. (1997). The interpolated SSS fields consist of the sum of a reference field (or first guess) and an anomaly field obtained by linear combination of satellite SSS data as follows:

$$
\mathbf{x}^{a}=\mathbf{x}^{f}+\mathbf{K}^{\mathrm{OI}}\left(\mathbf{y}^{o}-\mathbf{y}^{f}\right),
$$

where

$$
\mathbf{K}^{\mathrm{OI}}=\mathbf{C}_{\mathrm{ao}}\left(\mathbf{C}_{\mathrm{oo}}+\mathbf{R}\right)^{-1}
$$

$\mathbf{x}^{a}$ are the vectors of the estimates at the grid point and $\mathbf{y}^{\mathrm{o}}$ is the vector of observation, respectively; $\mathbf{x}^{f}$ and $\mathbf{y}^{f}$ are the vectors of the reference field values at the grid and observation points, respectively; $\mathbf{K}^{\mathrm{OI}}$ is the weight's matrix constructed from covariance and error matrix; $\mathbf{C}_{\mathrm{ao}}$ is the covariance matrix between the analyzed fields at the grid and observation points; $\mathbf{C}_{\text {oo }}$ is the covariance matrix between the observations; and $\mathbf{R}$ is the observation error matrix.

The SMOS and/or SMAP L3 SSS fields (Fig. 2) are mapped on an EASE horizontal grid with a resolution of $25 \mathrm{~km}$. The optimal analysis is calculated on anomalies relative to the 
reference field used as a first guess, that is, ISAS. The analysis modifies the first guess according to observations a priori statistics and chosen scales and covariance model. Thus, in poorly sampled areas or if the observational errors are relatively large, the solution may remain close to the reference field.

The covariance matrices $\mathbf{C}_{\mathrm{oo}}$ and $\mathbf{C}_{\mathrm{ao}}$ are constructed using the same covariance model $\mathbf{C}(d r, d t)$, using a Gaussian function of time and space:

$$
C_{i, j}(d r, d t)=\sigma_{i, j} \exp \left[-\left(\frac{d r_{i, j}^{2}}{2 L^{2}}+\frac{d t_{i, j}^{2}}{2 T^{2}}\right)\right],
$$

where $d r$ and $d t$ are the spatial and temporal distances and $L$ and $T$ are the associated decorrelation scales. The weight given at each scale of variability corresponds to the variance. The variance field $\sigma_{i, j}$ has been computed from filtered historical SMOS data (Fig. 3a; Boutin et al. 2018a). The error matrix for SMOS L3 data is derived from the model error provided by the L2 SMOS inversion and provided along with the L3 fields. Since no errors are provided along with SMAP L3 v3 fields, the SMOS errors are averaged in each OI box $\left(\sim 15^{\circ} \times 10^{\circ}\right)$ and applied to the SMAP data (Fig. 3b). The underlying assumption is that the error level in the two L3 products should be close but slightly smaller for SMAP L3 (Boutin et al. 2018a). Two optimal interpolations are used: a first to estimate the bias and a second to reproject and smooth the corrected data onto the EASE grid.

\section{b. Correction of seasonal and large-scale errors}

The first step consists in a first OI using Eq. (1). SMOS L3 and/or SMAP L3 SSS data are mapped over a period of 7 days separately for each satellite using a "large" correlation scale that is comparable to that used in ISAS. This large scale has been estimated to be on average $500 \mathrm{~km}$ in the tropics and subtropics. This correlation scale has been chosen empirically since the sampling strategy and the scale chosen for ISAS resolves on average a 500-km horizontal feature (Kolodziejczyk et al. 2015a; Table 1; see section S2 in the online supplemental material). This scale is introduced into the Gaussian correlation model [Eq. (3)], and the first OI is performed using the ISAS monthly fields as first guess (Gaillard et al. 2016). Smoothed seasonal and large-scale corrections are then deduced from the comparison of the SMOS and SMAP smoothed fields with ISAS SSS monthly fields interpolated for the corresponding analyzed weeks (Figs. 4 and 5). Note that, by construction the ISAS SSS fields are relaxed to climatology in regions where no in situ data are available (especially at high latitude). It is likely that in these regions the large-scale bias correction is less accurate.

In the tropical regions, SMOS L3 and SMAP L3 large-scale and seasonal systematic errors are reduced (Meissner et al. 2019; Boutin et al. 2018a) to values lower than 0.3 pss locally (Figs. 4 and 5). This is on the order of the expected uncertainty on SMOS and SMAP weekly gridded data (Boutin et al. 2018a). Thus, seasonal and large-scale corrections are relaxed within the tropics using a Gaussian function centered at this equator:

$$
\alpha(y)=1-e^{-y^{2} / l^{2}},
$$

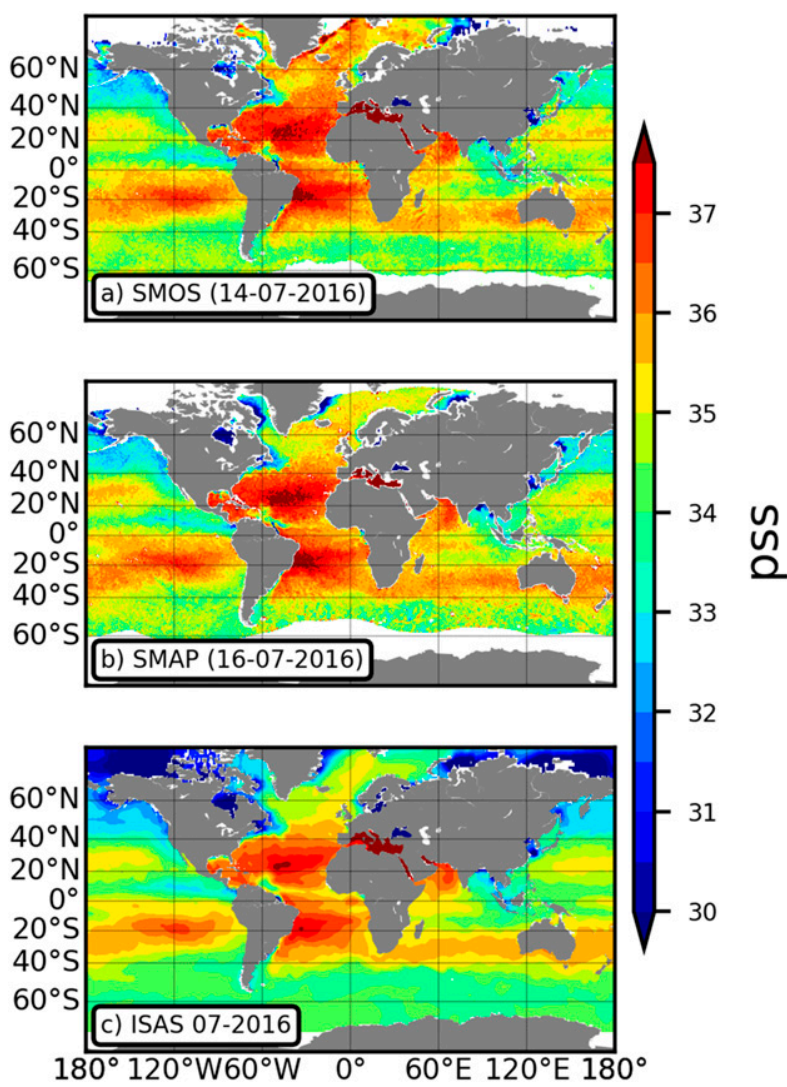

FIG. 2. (a) SMOS CEC L3 debias 9-day v3 SSS (pss) field on $15 \mathrm{Jul}$ 2016, (b) SMAP RSS 40-km 8-day v3 SSS (pss) field on $16 \mathrm{Jul}$ 2016, and (c) ISAS SSS monthly field (reference field) interpolated in August 2016.

where the length scale $l=30^{\circ}$ (Table 1 ). This relaxation allows to keep the information content in the data of the low salinity plume of large tropical river runoff as well as the tropical instability wave signature in SSS found in SMOS products (Yin et al. 2014). The large-scale correction is also relaxed in the Gulf of Mexico and off Rio de la Plata river mouth regions.

\section{c. Noise reduction and data mapping}

The corrected SMOS and SMAP L3 SSS are mapped using an interpolation scheme by introducing into the Gaussian function [Eq. (3)] spatial and temporal correlation scales corresponding to the synoptic scales resolved by SMOS and/or SMAP, i.e., 7 days and $25 \mathrm{~km}$ (Table 1).

\section{Results}

Example of resulting OI L4 SSS weekly fields combining SMOS and SMAP L3 fields are provided in Fig. 6a (15 July 2016). Using ancillary satellite SST (Fig. 6b), six extra L4 parameters are computed from combination between OI L4 SSS with SST using the TEOS-10 library (IOC, SCOR, and IAPSO 2010): density (Fig. 6c), spiciness (Fig. 6d), absolute salinity, conservative temperature, thermal expansion and haline contraction coefficients (section S3 in the online supplemental 
SMOS STD

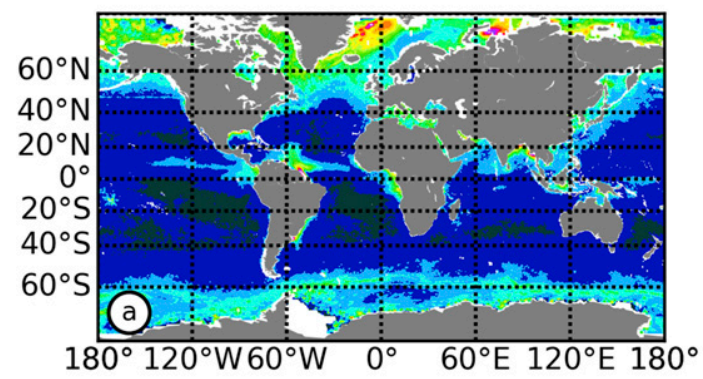

SMOS Error (15-07-2016)

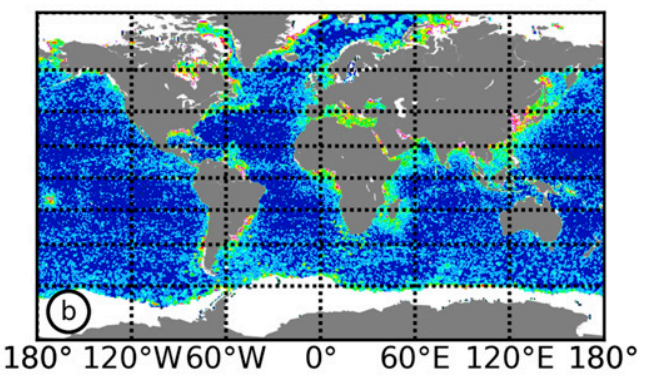

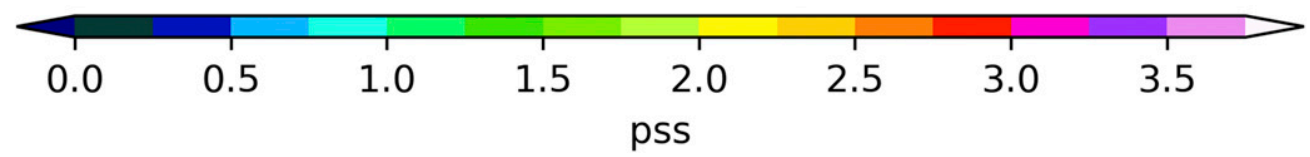

FIG. 3. (a) SMOS SSS STD computed over the period 2011-2017, and (b) example of SMOS error field on 15 Jul 2016 provided along with SMOS L3 fields. Both are used as a priori statistics in the OI.

material). Spiciness is defined as the density compensated anomaly of temperature/salinity along an isopycnal surface following McDougall and Krysik (2015). Here, the spiciness is assumed to be proportional to isopycnal temperature and salinity and is expressed in density units. The suggested orthogonality between density and spiciness isolines is not assumed in our definition (Flament 2002; Huang 2011), because this assumption is devoid of physical meaning (McDougall and Krysik 2015). This is a complementary parameter to temperature, salinity and density to characterize water masses contrasts (Portela et al. 2020). These thermodynamic and physical parameters are valuable for the oceanographic community since they comprehensively describe the upper-layer water masses, that is, heat, freshwater and buoyancy, formation and variability, especially the thermohaline characterization of the surface oceanic fronts (Kolodziejczyk et al. 2015a,b).

To illustrate the value of combining consistent SST and SSS to characterize the associated surface frontal dynamics, a snapshot (14 July 2016) of horizontal density gradient contributions have been computed in the North Atlantic following Kolodziejczyk et al. (2015a) using OI L4 SSS, SST, density and spiciness. To a first order, the density gradient is linearized according to the equation

$$
\nabla_{H} \rho=\rho_{0} \beta \nabla_{H} S-\rho_{0} \alpha \nabla_{H} T,
$$

where $\rho$ is the surface density, $S$ is the SSS from OI L4, Tis the SST from AMSR-E $/ 2$; and $\rho_{0}$ is constant $\left(=1026 \mathrm{~kg} \mathrm{~m}^{-3}\right)$. The $\alpha$ and $\beta$ are thermal expansion and haline contraction coefficients, respectively, computed from OI L4 SSS maps. The $\nabla_{H}$ gives the horizontal gradient. The absolute value of the thermal and haline contributions to the absolute density gradient are plotted in Figs. 7a and 7b, respectively. In addition, the absolute value of density gradient and spiciness gradient computed from TEOS-10 and OI L4 SSS fields are shown in Figs. $7 b$ and $7 c$, respectively.

In July 2016, in the subtropical North Atlantic, the Gulf Stream extension is characterized by both complex temperature and salinity double frontal structure just northward and southward of $40^{\circ} \mathrm{N}$. The thermohaline front along the Gulf Stream extension is set up by the meeting of southward flow of the cool and fresh Labrador Current with the northward flow of warm and salty water of subtropical origin. Although the distribution of multiple haline and thermal fronts is not exactly the same, major mesoscale features of the front (inertial current, meanders, and eddy) are consistently observed in location and intensity in both temperature and salinity gradients (Reul et al. 2014b). This results in strongly compensated thermohaline fronts that therefore exhibit weak signature in sea surface density (Fig. 7c). In contrast, the spiciness gradient (Fig. 7d) is enhanced to twice the amplitude of temperature and salinity individual contributions to density gradient (Figs. 7a,b), suggesting a strongly compensated front. This thermohaline feature is ubiquitous in various frontal regions, mode water formation hot spots, and associated with processes such as mixing and cabbeling (Thomas and Shakespeare 2015; Stewart et al. 2017). SSS distribution in the western tropical Atlantic

TABLE 1. Parameters used in the successive optimal interpolation.

\begin{tabular}{|c|c|c|}
\hline Parameter & Value & Comments \\
\hline L(OI1) & $500 \mathrm{~km}$ & $\begin{array}{l}\text { Space scale used for mapping separately } \\
\text { L3 SMOS and SMAP SSS at large scale } \\
\text { during first OI }\end{array}$ \\
\hline L(OI2) & $25 \mathrm{~km}$ & $\begin{array}{l}\text { Space scale used for merging and mapping } \\
\text { of corrected L3 SMOS and SMAP at } \\
\text { "mesoscale" during the second OI }\end{array}$ \\
\hline $\mathrm{T}(\mathrm{OI} 2)$ & 7 days & $\begin{array}{l}\text { Time scale used for the merging and } \\
\text { mapping of corrected L3 SMOS and } \\
\text { SMAP at "mesoscale" during the } \\
\text { second OI; note that the time window of } \\
\text { selected data for weekly mapping is } \\
10 \text { days }\end{array}$ \\
\hline 1 & $30^{\circ}$ & $\begin{array}{l}\text { Meridional scale for the relaxation of the } \\
\text { large scale and time bias correction }\end{array}$ \\
\hline
\end{tabular}


SMOS corr. (14-07-2016)

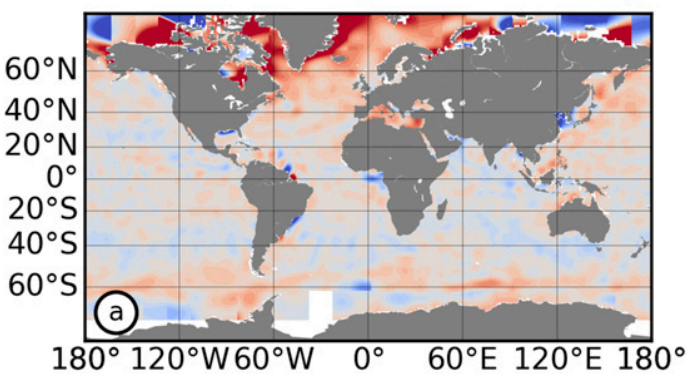

SMAP corr. (16-07-2016)

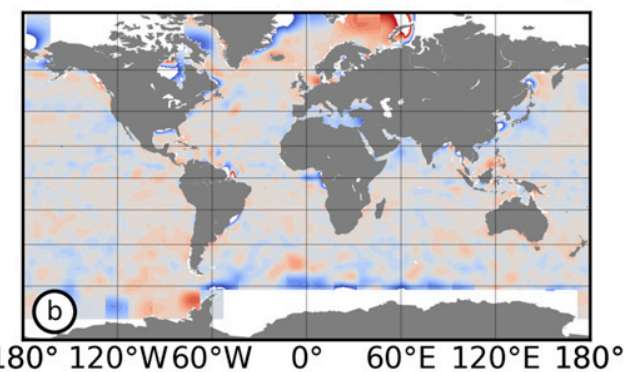

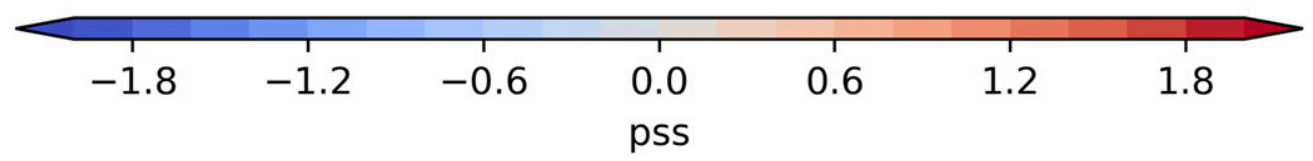

FIG. 4. Large-scale SSS differences between ISAS and (a) SMOS L3 SSS during 14 Aug 2016 and (b) SMAP L3 SSS during $16 \mathrm{Jul} 2016$ as deduced from first OI.

region (Fig. 7a) reveals the Amazon river plume associated with intense freshwater release in the surface western tropical Atlantic (Fig. 7a), which only has a weak temperature signature (Fig. 7b). The associated density front (Fig. 7b) is thus mainly explained by the salinity gradient contribution. On the other hand, north of $50^{\circ} \mathrm{N}$ along the Labrador current $\left(55^{\circ} \mathrm{W}\right)$ the salinity gradient also dominates the weakly compensated density front (Figs. 7c,d). These few examples illustrate the high variability of thermohaline characteristics of the fronts over the ocean surface (not always compensated).

\section{Validation}

OI L4 SSS satellite products have been collocated with available independent in situ observations mainly provided by TSG data from ships of opportunity. The collocation is performed pairing each TSG measurement with the occupied satellite pixel. The statistics have been separated into two regions: first, the latitudes between $60^{\circ} \mathrm{S}$ and $60^{\circ} \mathrm{N}$ and, second, the subpolar regions and Arctic Seas poleward of $60^{\circ} \mathrm{N}$. To compare and quantify the improvement from L3 products from SMOS and/or SMAP resulting from the OI procedure, only SSS collocations that are common to each product (viz., ISAS, satellite OI L4 SSS, and SMOS L3 for the period from 2011 to 2017, and SMAP L3 for the period from 2015 to 2017) are considered. Indeed, to be comparable, statistics should be based on the same set of colocalized data for the four products; that is, if collocated data are unavailable for one of the products, the collocation is discarded.

\section{a. Low-to-midlatitudes}

Over the SMOS-only period between 2011 and 2014, within $60^{\circ} \mathrm{S}-60^{\circ} \mathrm{N}$ the satellite OI L4 SSS, when compared with the TSG data, shows a mean difference and root-mean-square difference (RMSD) of 0.09 and 0.66 pss, respectively (Table 2). Over the SMOS/SMAP period (2015-17), the mean difference
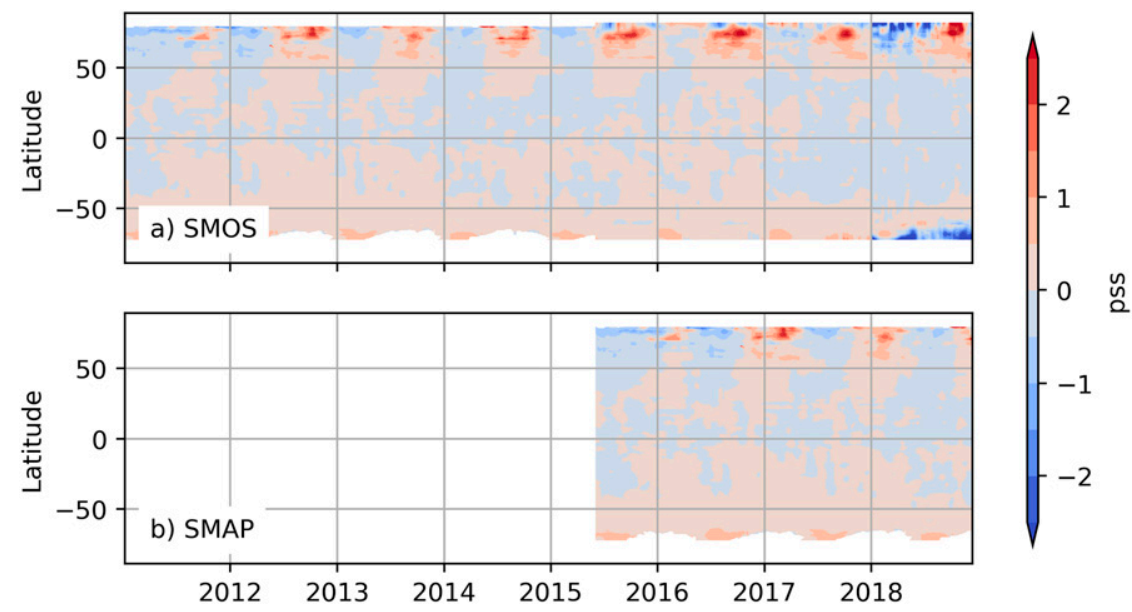

FIG. 5. Large-scale and seasonal SSS differences between ISAS and (a) SMOS L3 SSS and

(b) SMAP L3 zonally integrated as deduced from first OI. 

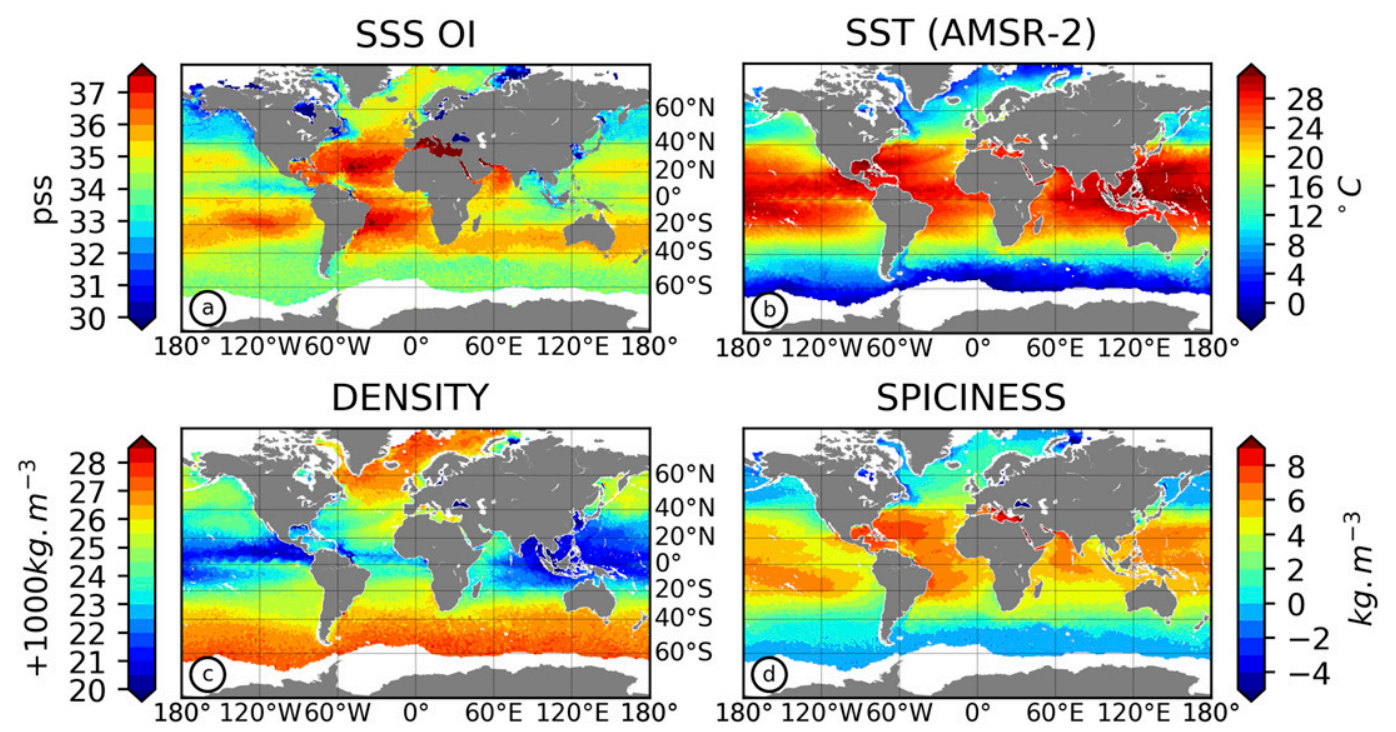

FIG. 6. The 15 Jul 2016 map of (a) satellite OI L4 SSS, (b) AMSR-2 SST, (c) L4 sea surface density, and (d) L4 sea surface spiciness. Both are computed from satellite OI L4 SSS and AMSR-2 SST maps. Panels (c) and (d) are derived from the (a) and (b) maps.

and RMSD are -0.01 and 0.37 pss, respectively (Table 2). Over the 2015-17 period, SMOS L3 product and SMAP L3 global products exhibit larger values for RMSD (0.52 and 0.53 pss, respectively) and with average mean difference ( 0.07 and 0.01 , respectively). Over this period, if we consider only the SMOS L3 data in the interpolation (Table 2), the statistics are slightly better than the one of SMOS L3 or SMAP L3, but not as good than when using both satellites. This shows the value of adding the SMAP L3 data to SMOS L3 data over this period to improve the SSS estimates. Last, the correlation coefficients for satellite OI with TSG SSS shows improved values up to 0.89 over the period 2011-14, and 0.93 over the period 2015-17, relative to SMOS L3, and for SMAP L3 (Table 2). Although the differences may result from increased accuracy of the SSS estimates using both satellites over the last period, the SMAP L3 SSS coastal mask extends further off the coast, resulting in
SSS
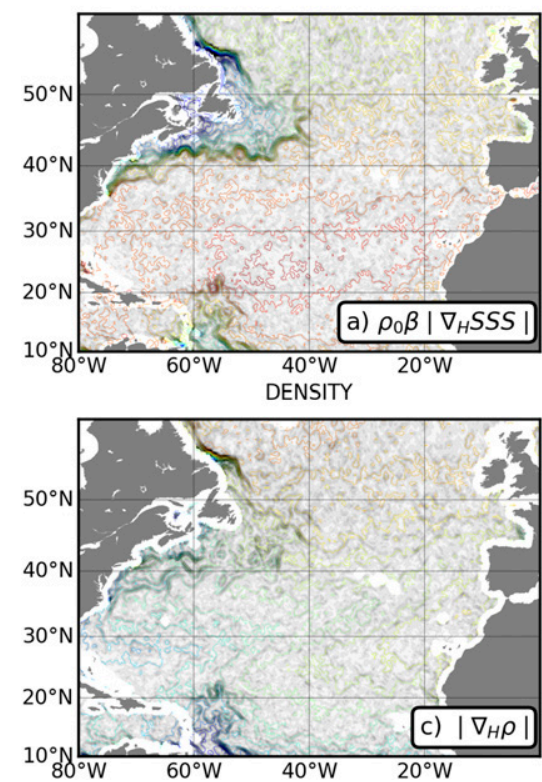

SST
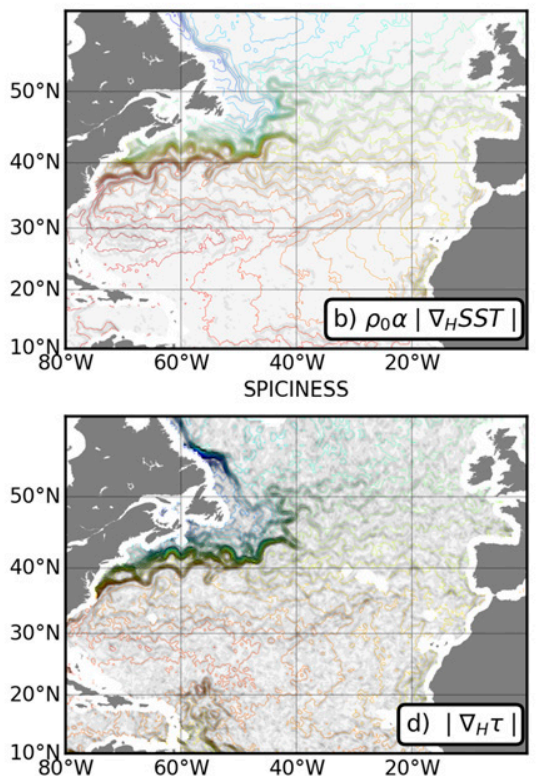

2.8

2.4

2.0 $-1.6 \frac{1}{\frac{1}{2}}$ $1.2 \stackrel{8}{\stackrel{2}{2}}$ $-0.8$ $-0.4$ $-0.0$

FIG. 7. Contributions to horizontal surface density gradient (gray shading) on 14 Jul 2016 computed from (a) OI L4 SSS $\left(\mathrm{kg} \mathrm{m}^{-3}\right)$, (b) AMSR-2 SST $\left(\mathrm{kg} \mathrm{m}^{-3}\right)$, (c) L4 sea surface density $\left(\mathrm{kg} \mathrm{m}^{-3}\right)$, and (d) L4 sea surface spiciness $\left(\mathrm{kg} \mathrm{m}^{-3}\right)$. The contours are isocontours of the plotted parameter, and the contour scale is the same as in Figs. 6a-d for (a)-(d), respectively. 
TABLE 2. Root-mean-square difference, mean difference (bias), and correlation for SNO SSS TSG (between $\sim 60^{\circ} \mathrm{N}$ and $60^{\circ} \mathrm{S}$ ) collocation with satellite SSS from OI L4 [for SMOS only and SMOS/SMAP (in boldface type)], SMOS L3, SMAP L3 and ISAS products.

\begin{tabular}{|c|c|c|c|c|c|c|c|c|c|}
\hline & 2011 & 2012 & 2013 & 2014 & 2011-14 & 2015 & 2016 & 2017 & $2015-17$ \\
\hline$N$ & 526377 & 627066 & 512313 & 498349 & 2164105 & 205857 & 408964 & 248576 & 863397 \\
\hline \multicolumn{10}{|l|}{ RMSD } \\
\hline OI L4 & 0.59 & 0.67 & 0.68 & 0.68 & 0.66 & 0.46 & 0.36 & 0.28 & 0.37 \\
\hline OI (SMOS only) & & & & & & 0.40 & 0.38 & 0.31 & 0.37 \\
\hline SMOS L3 & 0.76 & 0.99 & 0.83 & 0.82 & 0.86 & 0.55 & 0.53 & 0.46 & 0.52 \\
\hline SMAP L3 & & & & & & 0.59 & 0.51 & 0.51 & 0.53 \\
\hline ISAS & 0.59 & 0.70 & 0.68 & 0.72 & 0.67 & 0.51 & 0.44 & 0.24 & 0.41 \\
\hline \multicolumn{10}{|l|}{ Bias } \\
\hline OI L4 & 0.07 & 0.09 & 0.11 & 0.08 & 0.09 & 0.01 & -0.01 & -0.03 & -0.01 \\
\hline OI (SMOS only) & & & & & & 0.00 & -0.02 & -0.04 & -0.02 \\
\hline SMOS L3 & -0.11 & -0.05 & 0.16 & 0.06 & 0.01 & 0.09 & 0.11 & -0.01 & 0.07 \\
\hline SMAP L3 & & & & & & 0.04 & 0.00 & -0.05 & 0.01 \\
\hline ISAS & 0.09 & 0.12 & 0.12 & 0.09 & 0.11 & 0.03 & 0.00 & -0.03 & 0.00 \\
\hline \multicolumn{10}{|l|}{ Correlation } \\
\hline OI L4 & 0.91 & 0.90 & 0.85 & 0.91 & 0.89 & 0.93 & 0.95 & 0.90 & 0.93 \\
\hline OI (SMOS only) & & & & & & 0.94 & 0.95 & 0.88 & 0.93 \\
\hline SMOS L3 & 0.86 & 0.77 & 0.77 & 0.86 & 0.81 & 0.90 & 0.89 & 0.80 & 0.87 \\
\hline SMAP L3 & & & & & & 0.88 & 0.90 & 0.78 & 0.86 \\
\hline ISAS & 0.92 & 0.89 & 0.86 & 0.90 & 0.89 & 0.91 & 0.92 & 0.92 & 0.92 \\
\hline
\end{tabular}

much better statistics for the open ocean (Kolodziejczyk et al. 2016; Boutin et al. 2018a). Overall, in the subtropics and at midlatitude, satellite OI SSS have improved the L 3 products by $23 \%$ in term of RMSD. The RMSD and bias include differences with TSG SSS measurements due to both misfit and representativeness error (i.e., difference from in situ subsurface salinity and skin SSS as well as subfootprint SSS variability). To put these overall statistics into perspective, it should be noted that ISAS OI, which provides large-scale smoothed SSS fields, exhibit comparable RMSD, mean difference and correlation with TSG to OI L4 SSS (Table 2). These high levels of correlation reveal the dominant weight of the large-scale coherency. This gain in coherency is provided by large-scale bias correction proposed in this study.

However, it is admitted that the SMOS and SMAP are able to resolve mesoscale features at low to midlatitude (e.g., Yin et al. 2014; Reul et al. 2014b; Kolodziejczyk et al. 2015a), while ISAS is smoothing out these features (Kolodziejczyk et al. 2015a). Hence, more refined statistics are needed to provide accurate assessment of the SSS products capability. First, these global statistics hide large year-to-year variability. Between 2011 and 2017, OI L4 SSS yearly RMSD range from 0.28 to 0.68 pss, outperforming the other products (Table 2). The better statistics over the SMOS/SMAP period results from the SMAP L3 mask that reduces the near-coast collocations with largest differences with in situ measurements, but also mainly from merging the two satellite data (Table 2).

Second, these global statistics hide very inhomogeneous distributions of SSS differences. Between 2011 and 2017 (Fig. 8), the OI L4 SSS product locally presents SSS differences generally lower than 0.5 pss in every region over the open ocean where in situ TSG are available (Fig. 8a). These statistics are contrasting with validation results for individual SMOS L3 and SMAP L3 products that do not have large-scale and seasonal bias absolute correction procedures, and present larger differences in the North Atlantic midlatitudes, north-eastern Atlantic and around the European continent, but also in the Southern Ocean (Figs. 8b,c). In addition, in regions of high SSS variability, such as river plumes, satellite OI L4 SSS fields present differences much lower than ISAS SSS fields (Figs. 8a,d).

Third, to check the effective capability of the satellite OI L4 SSS product to monitor the mesoscale features, the OI L4 SSS were systematically colocalized and compared with individual TSG SSS transects. Figure 9 shows two examples at subpolar latitudes where the seasonal and latitudinal bias is pronounced in SMOS and SMAP L3 products (Figs. 2a,b). In the North Atlantic (Fig. 9a), the difference of TSG SSS (black dots) with SMOS L3 (blue dots) and SMAP L3 SSS (cyan dots) varies along the transects at larger scale than the mesoscale SSS variability (e.g., between 17 and 19 June 2016; Fig. 9a). The satellite OI correction (red dots) allows to better fit the TSG SSS, since the ISAS SSS is consistent at large scale with the independent TSG SSS. In the Southern Ocean, the SMOS L3 and SMAP L3 latitudinal biases are less pronounced (Fig. 5). Although both satellite OI L4 SSS and L3 SSS products present a good agreement with mesoscale features observed in the TSG data, satellite OI L4 reduce the large noise in the most southern part of the transect (Fig. 9b; between 1 and 3 March 2016).

To evaluate the SSS horizontal effective resolution and coherency of the mesoscale SSS feature captured with the satellite products, we compute the spectra and coherency spectra between TSG SSS and OI L4 SSS (Boutin et al. 2018a). Two regions were chosen to test that for the present study: (i) the North Atlantic subtropical SSS maximum $\left(50^{\circ}-20^{\circ} \mathrm{W}, 10^{\circ}-40^{\circ} \mathrm{N}\right)$, where 88 transects are available between 2011 and 2016, and 
L4 OI

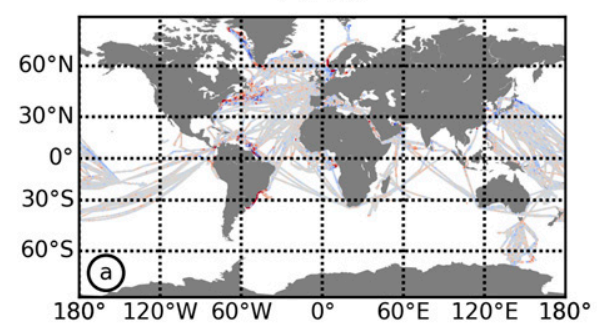

L3 SMAP

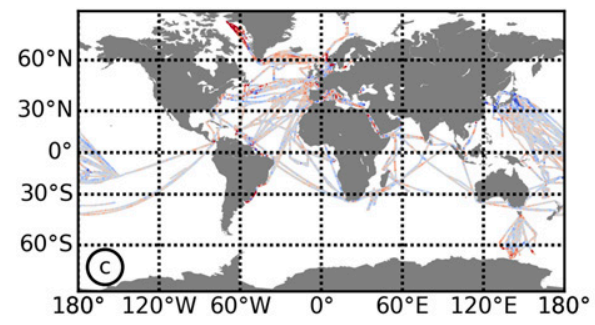

L3 SMOS

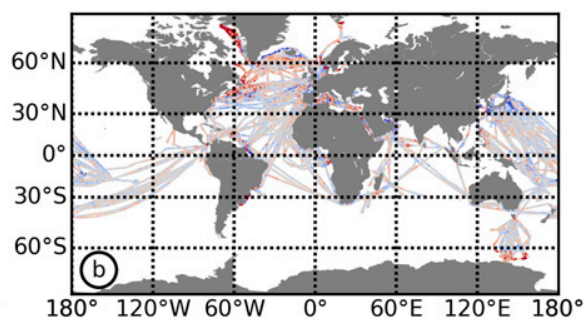

ISAS

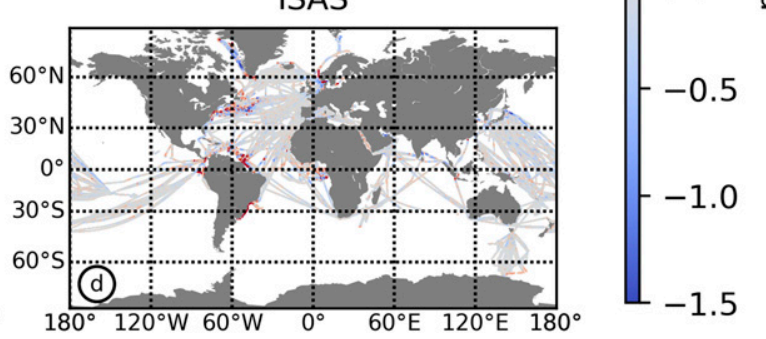

FIG. 8. Difference with in situ SSS from French "Service National d'Observation" SSS TSG during 2011-17 for (a) OI L4; (b) SMOS L3; (c) SMAP L3; (d) ISAS.

(ii) the tropical Atlantic $\left(40^{\circ}-10^{\circ} \mathrm{W}, 5^{\circ} \mathrm{S}-20^{\circ} \mathrm{N}\right)$, where 26 transects are available between 2014 and 2016 (Fig. 10). These two regions have been chosen because of the exceptional amount of repeated available transects. Individual transects were visually inspected and incomplete transects were discarded. To reduce uncertainty due to noisy individual spectrum from each individual transect, spectra were averaged in each of the two regions.

The horizontal SSS coherency spectra refer to the coherency of the SSS horizontal variability between the collocated TSG SSS and SSS satellite products, i.e., the level of correlation of the SSS signal for a given wavelength range. This allows us to assess how well the OI L4 SSS products observe mesoscale features larger than $50 \mathrm{~km}$ scale in presence of data noise and spurious SSS contamination.

In the subtropical North Atlantic (Figs. 10a,b), TSG (black) and satellite OI L4 SSS (red) spectra show a good agreement between 125 and $1000 \mathrm{~km}$. In contrast, in spite of comparable slopes, the SMOS L3 SSS (blue) and SMAP L3 SSS (cyan) spectra show a slightly larger amplitude than the TSG SSS spectrum. This suggests that for this range of wavelengths the variance of mesoscale features is probably noisier in SMOS L3 and SMAP L3 SSS products. Interestingly, the coherency spectra of collocated satellite OI L4 and TSG SSS exhibit a slightly higher values in comparison with SMOS L3 coherency from large scale (coherency $>0.5$ for wavelength $>1000 \mathrm{~km}$ ) to mesoscale (coherency of $\sim 0.25$ for wavelength of $\sim 300 \mathrm{~km}$ ). The SMAP L3 product shows a drop of coherency between wavelengths of $700-400 \mathrm{~km}$ but a slightly better coherency for wavelengths close to $300 \mathrm{~km}$. The significance at $95 \%$ is lost for wavelengths smaller than $250 \mathrm{~km}$. This suggests that wavelengths shorter than $300 \mathrm{~km}$ are poorly represented in the products and/or appear with different characteristics due the different spatiotemporal sampling by satellite and TSG. This is
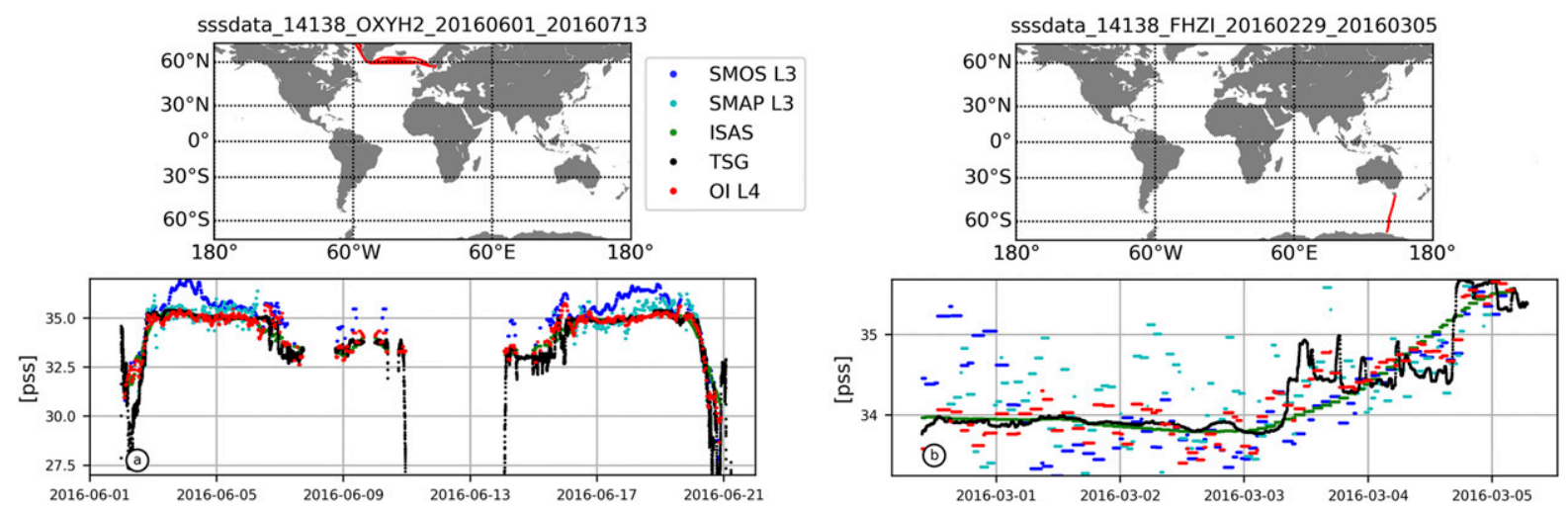

FIG. 9. (a) TSG SSS transect between 1 and 22 Jun 2016 across the North Atlantic (black); collocated satellite OI L4 SSS (red), SMOS L3 (blue), and SMAP L3 (cyan); (b) TSG SSS transect between 29 Feb and 5 Mar 2016 across the Southern Ocean. Transect locations are given on the maps above the panels. 


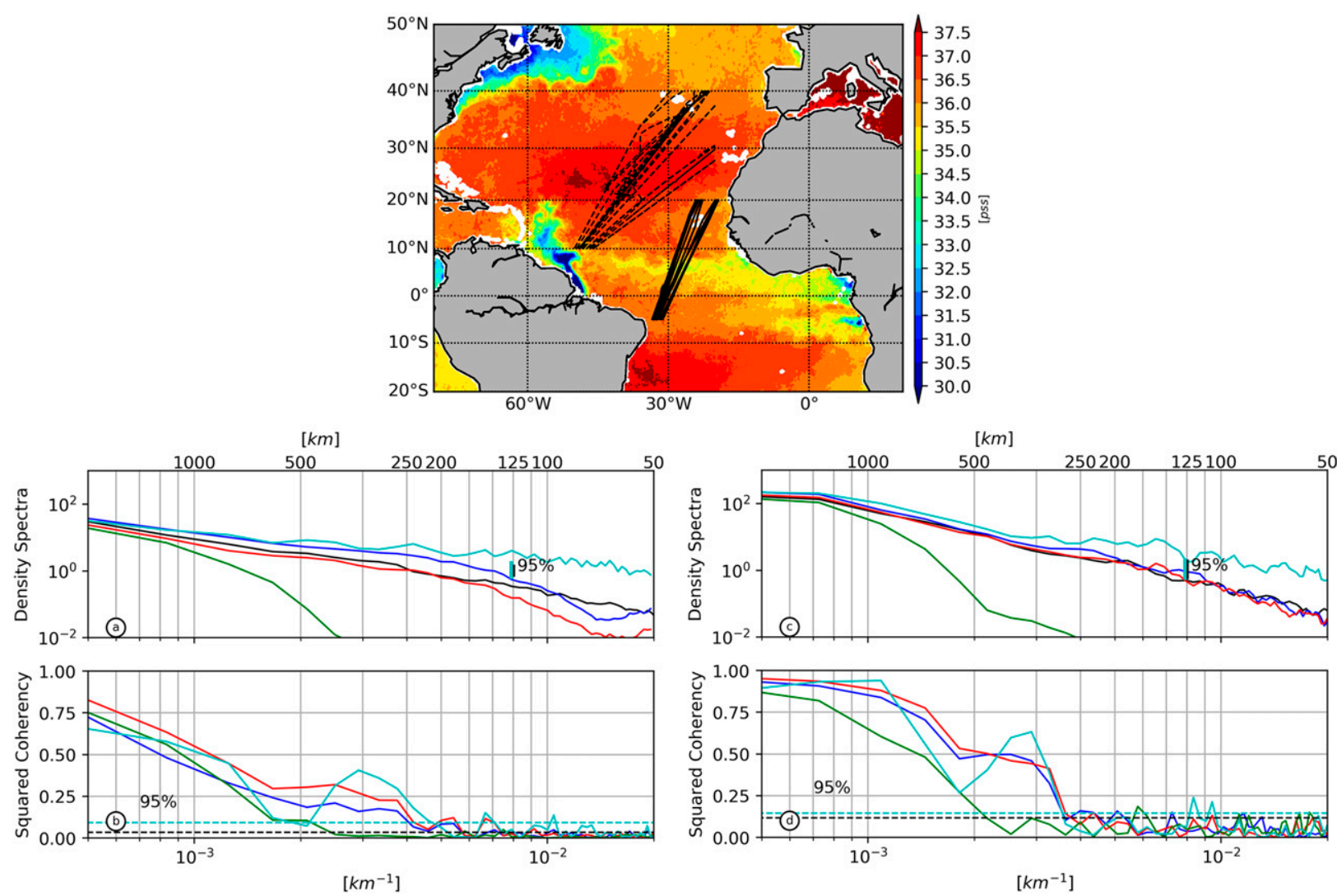

FIG. 10. (a) Density spectra computed from 88 SSS TSG transects (black), collocated OI L4 SSS (red), SMOS L3 SSS (blue), SMAP L3 SSS (cyan), and ISAS SSS (green) across the subtropical North Atlantic box $\left(50^{\circ}-20^{\circ} \mathrm{W} / 10^{\circ}-40^{\circ} \mathrm{N}\right.$; dashed black in Atlantic map above the panels). (b) Coherency spectra between TSG SSS transects and collocated OI L4 SSS (red), SMOS L3 SSS (blue), SMAP L3 SSS (cyan), and ISAS SSS (green). (c) As in (a), but for 26 transects across the tropical Atlantic box $\left(40^{\circ}-10^{\circ} \mathrm{W} / 5^{\circ} \mathrm{S}-20^{\circ} \mathrm{N}\right.$; solid black in Atlantic map above the panels). (d) As in (b), but for the tropical Atlantic. Dashed horizontal [in (b) and (d)] or vertical lines [in (a) and (c)] indicate the level of significance at $95 \%$ for SMOS L3 and OI L4 (black) and SMAP L3 (cyan).

consistent with a previous study on SMOS L3 product assessment (Boutin et al. 2018a).

In the tropical Atlantic (Figs. 10c,d), TSG and SMOS SSS spectra show very similar behaviors, with comparable variance and slope values. Furthermore, both spectra also show a relatively high level of coherence at wavelengths larger than $300 \mathrm{~km}$. In the tropical Atlantic region, the coherency drop-off observed at wavelengths smaller than $250 \mathrm{~km}$ suggests that the satellite products are not able to consistently resolve scales smaller than $\sim 125-150 \mathrm{~km}$ (using scale as $1 / 2$ of the wavelength).

In general, in the subtropical and tropical Atlantic Oceans, the OI L4 SSS product is able to resolve wavelengths on the order of $300 \mathrm{~km}$. In the tropical region, considering a threshold for a coherency at 0.5 , the OI L4 SSS resolve wavelengths slightly smaller than $300 \mathrm{~km}$. In the subtropical region, the coherency is lower but significant (at 95\%) for wavelengths down to $250 \mathrm{~km}$. In any case, the OI L4 SSS reduces noise and improves accuracy compared with SMAP and SMOS L3 products. These wavelengths correspond to effective resolved horizontal scales on the order of $150-125 \mathrm{~km}$ (meanders and eddies). Nevertheless, the misfit between TSG and satellite data is not only due to spurious satellite data. Incoherency resulting from differences between instantaneous and pointwise measurements from the TSG data and colocalized satellite products ( $\sim 7$ days; $50 \mathrm{~km}$ ) may be responsible for shift and lag between TSG SSS measurements and collocated satellite OI SSS along ship transects. This results in a loss of coherency for the smaller and faster SSS mesoscale structures.

\section{b. High latitudes: Arctic seas}

SSS retrievals in the Arctic seas present poor signal-to-noise ratio. Over the period 2011-14 (SMOS), the satellite OI L4 SSS exhibits an RMSD, mean difference, and correlation of 1.78 , 0.23 pss, and 0.91, respectively (Table 3). Over the period 2015-17 (SMOS/SMAP), satellite OI L4 SSS present an RMSD, mean difference, and correlation of $0.78,0.05 \mathrm{pss}$, and 0.88 , respectively. In comparison, over the complete period 2011-17 the SMOS L3 and SMAP L3 SSS product exhibit generally larger RMSD, mean difference and but smaller correlations (Table 3). The SMAP ice mask extends further offshore and away from the ice edge than the SMOS one, which could explain the improved statistics over the period 2015-17. However, the satellite OI L4 including additional SSS data 
TABLE 3. As in Table 2, but with RMSD, bias, and correlation (using an outlayers filtering at $3 \sigma$ ) for in situ data in the Arctic (north of $\left.60^{\circ} \mathrm{N}\right)$.

\begin{tabular}{|c|c|c|c|c|c|c|c|c|c|}
\hline & 2011 & 2012 & 2013 & 2014 & 2011-14 & 2015 & 2016 & 2017 & 2015-17 \\
\hline$N$ & 24242 & 56741 & 107441 & 50256 & 238680 & 9400 & 16147 & 13568 & 39115 \\
\hline \multicolumn{10}{|l|}{ RMSD } \\
\hline OI L4 & 0.87 & 1.80 & 1.98 & 1.61 & 1.78 & 0.73 & 1.03 & 0.35 & 0.78 \\
\hline OI SMOS only & & & & & & 0.78 & 1.06 & 1.00 & 0.98 \\
\hline SMOS L3 & 1.05 & 2.75 & 2.19 & 3.61 & 2.61 & 1.21 & 1.09 & 1.06 & 1.11 \\
\hline SMAP L3 & & & & & & 1.35 & 1.09 & 0.59 & 1.02 \\
\hline ISAS & 0.85 & 1.99 & 2.02 & 1.34 & 1.80 & 0.69 & 1.03 & 0.36 & 0.77 \\
\hline \multicolumn{10}{|l|}{ Bias } \\
\hline OI L4 & 0.03 & 0.92 & -0.42 & 0.93 & 0.23 & 0.13 & 0.02 & 0.02 & 0.05 \\
\hline OI SMOS only & & & & & & 0.12 & 0.00 & 0.11 & 0.07 \\
\hline SMOS L3 & -0.02 & 1.80 & 0.52 & 2.79 & 1.25 & 0.40 & 0.24 & 0.30 & 0.30 \\
\hline SMAP L3 & & & & & & 0.51 & 0.17 & 0.10 & 0.23 \\
\hline ISAS & 0.11 & 0.92 & -0.48 & 0.81 & 0.18 & 0.13 & 0.02 & 0.03 & 0.05 \\
\hline \multicolumn{10}{|l|}{ Correlation } \\
\hline OI L4 & 0.90 & 0.93 & 0.88 & 0.96 & 0.91 & 0.94 & 0.81 & 0.91 & 0.88 \\
\hline OI SMOS only & & & & & & 0.93 & 0.77 & 0.80 & 0.82 \\
\hline SMOS L3 & 0.76 & 0.88 & 0.83 & 0.83 & 0.83 & 0.80 & 0.73 & 0.75 & 0.75 \\
\hline SMAP L3 & & & & & & 0.81 & 0.79 & 0.90 & 0.83 \\
\hline ISAS & 0.96 & 0.95 & 0.91 & 0.97 & 0.94 & 0.97 & 0.83 & 0.95 & 0.91 \\
\hline
\end{tabular}

such as SMAP L3 still allows to reduce the RMSD and bias (Table 3) in the Arctic Basin.

In the Nordic seas and western Barents Sea, the OI SSS presents small differences with respect to in situ measurements (Fig. 11a). This is clearly due to the large-scale correction using the ISAS fields (Fig. 11d). In the Siberian marginal seas and in the Beaufort Gyre, the differences are significantly larger due to the inaccuracy of ISAS climatology in the absence of in situ data, as well as uncertain SMOS and SMAP retrievals in the cold water areas and in the vicinity of the sea ice edge. In the Nordic seas and Barents Sea, the SMOS L3 and SMAP L3 data are generally too salty (Figs. 11b,c).

The comparison of the SSS from the different products with the TSG SSS from S/V Tara sailing ship transects during 2013 (Figs. 12a,b) illustrates the expected improvements using the OI correction procedure (red curve; Fig. 12a). It is shown that the effectiveness of the correction depends on a first hand on the accuracy of the climatology used. In the Nordic seas, Barents Sea, and Siberian marginal seas as well as Beaufort Basin and Baffin Bay (except in Kara Sea), the relative agreement between OI SSS and TSG SSS is closely related to the ISAS and TSG SSS agreement. This also allows to correct the strongest anomalous SMOS L3 SSS such as in Beaufort Gyre and Baffin Bay (blue curve, Figs. 12b, 11). However, in the Kara Sea, an inaccurate ISAS climatology prevents us from effectively correct the SMOS L3 SSS (Fig. 12b). Despite a general improvement of SSS estimate in the Arctic Ocean, retrieving accurate SSS from L-band measurement in cold water and in the vicinity of sea ice edge require further research.

\section{Discussion and conclusions}

A new procedure for adjusting large-scale and time-varying bias on SMOS and SMAP L3 products has been presented.
With respect to latitudinal and seasonal varying corrections applied in SMOS and SMAP processing up to level 3, this procedure allows to adjust large-scale biases that vary regionally and interannually. This procedure uses successive optimal interpolations. A first optimal interpolation using a large covariance scale to estimate the large-scale difference between Argo monthly climatology and interpolated SMOS and SMAP L3 data. Then, a second optimal interpolation is used to merge and map SMOS and SMAP L3 products, after having corrected them from large-scale biases determined in the first step. This new procedure provides a significant improvement of the SSS satellite products. The resulting OI L4 SSS product presents a reduced signal-to-noise ratio in comparison to the SMOS and SMAP L3 products with the same time resolution (between 7 and 9 days). The improvement from L3 SSS products comes mainly from the seasonal and large-scale bias correction. Furthermore, over the period 2015-17, including both SMOS and SMAP L3 data provides improved estimates of SSS since we double the SSS data input in our OI. In the tropical open ocean, where the scale and time-varying bias is smaller than the error RMSD differences estimated from the comparison with TSG (Boutin et al. 2018a), additional correction to existing corrections performed in SMOS and SMAP processings up to level 3 is not required. Eventually, for the first time, the gain in resolution of such combination of consistent L4 SSS and SST satellite maps provides density, spiciness and thermodynamical variables computed from satellite SSS and SST. The hydrological and thermodynamical parameters provide a comprehensive insight in global sea surface water masses properties especially thermohaline contributions to mesoscale frontal variability (Kolodziejczyk et al. 2015a,b).

The large-scale correction presented in this study was initially developed from SMOS L2 and L3 data with the aim of getting SSS fields resolving large mesoscale features. Since 

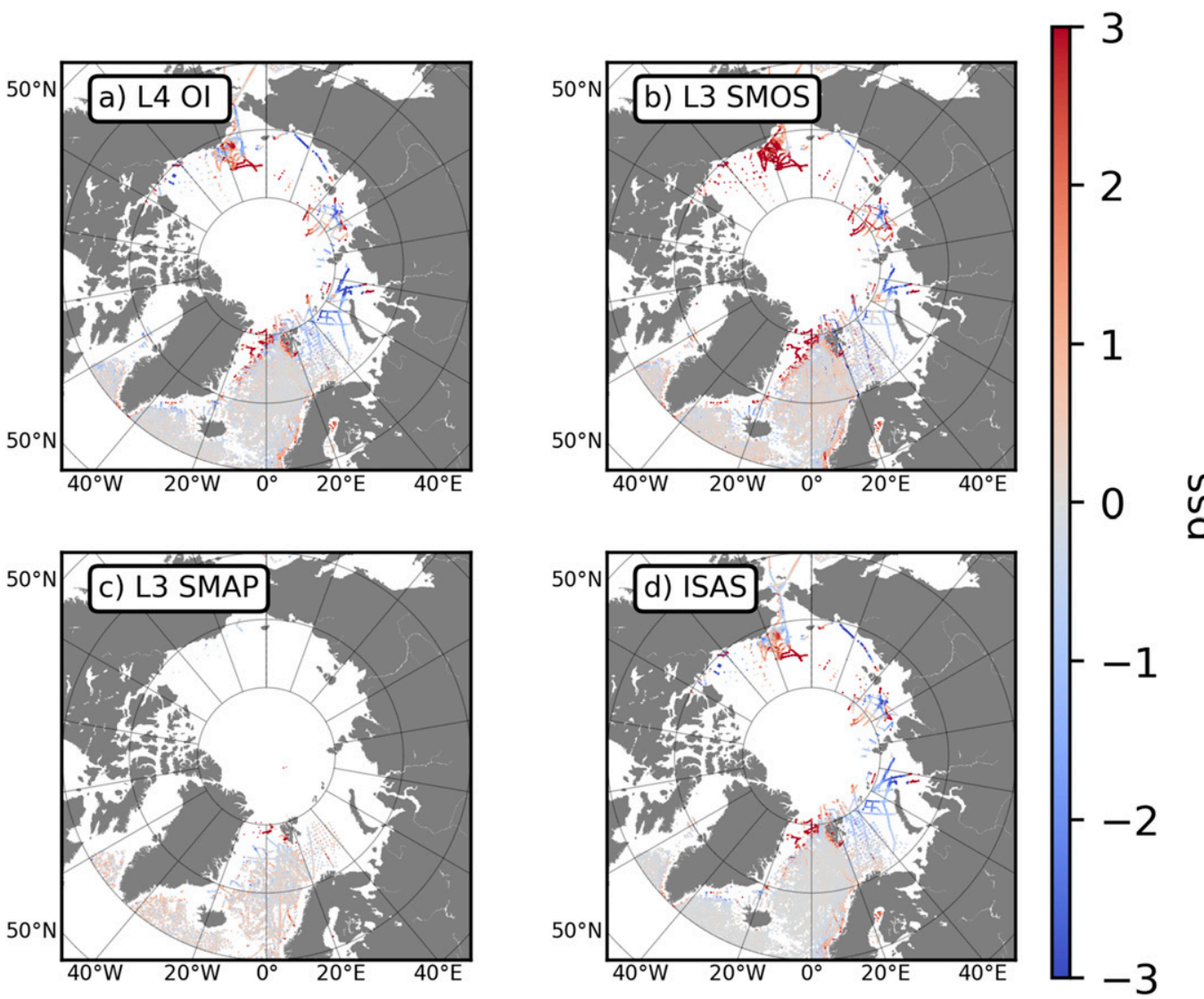

$\frac{n}{2}$

FIG. 11. Comparison with in situ SSS from available Arctic near surface in situ measurements (TSG, CTD, and Argo) over the period 2011-17 for (a) OI L4, (b) SMOS L3, (c) SMAP L3, and (d) ISAS.

SMAP SSS presents about the same time and space resolution as SMOS SSS and a comparable satellite swath, the correction and merging approach also fits the SMAP SSS. Although Aquarius satellite is an important source of satellite SSS data, it was not considered in this study for the following reasons: SMOS and SMAP have about the same resolutions $(\sim 45 \mathrm{~km})$, large swath width on the order of thousands of kilometers, allowing revisit time on the order of 3 days, while Aquarius has only a 150-km effective resolution (Lee et al. 2012), a swath width of $\sim 300 \mathrm{~km}$, and a revisit time of 7 days. Moreover, a strategy for adjusting Aquarius satellite SSS with Argo SSS has already been presented in Melnichenko et al. (2014) and substantially differ from our approach.

Although the OI approach is commonly used to intercalibrate and map multisatellite SST L4 products (Autret et al. 2019; Reynolds and Smith 1994), the OI L4 SSS satellite products merging SSS data retrieved from different L-band sensors remain uncommon. Melnichenko et al. (2014) used OI scheme to map Aquarius alone and corrected interswath biases providing $O(150 \mathrm{~km})$ and $\mathrm{O}(1$ week) corrected SSS maps. Buongiorno Nardelli (2012) used OI to map in situ SSS using a multidimensional correlation function involving satellite SST gradients to extrapolate SSS at smaller resolution than permitted by in situ data. They also provided "high resolution"
SSS map and sea surface density (SSD) maps (Droghei et al. 2016). This approach was also adapted to provide high resolution SSS maps from SMOS SSS (Buongiorno Nardelli et al. 2016). Although, this approach can potentially provide SSS and SSD fields at a finer resolution, assuming the SST and SSS gradients correlation is a strong hypothesis and its validity is limited to certain times and locations (Kolodziejczyk et al. 2015a,b).

The approach we follow here differs from the one followed for developing the CCI+SSS (Boutin et al 2019) product using the three historical L-band radiometer missions measuring SSS from space, i.e., Aquarius (Lagerloef 2012), SMAP and SMOS. Actually, the Climate Change Initiative (CCI+SSS), as well as the SMOS L3 CATDS methodology, is based on the selfconsistency of the satellite SSS measured in different geometries and, in the case of CCI+SSS, with different sensors. It requires a good characterization of the random and systematic errors coming from both the satellite observing system and the sampling error, hence a good knowledge of the satellite SSS error sources and of the SSS natural variability between various satellite passes. As a result, the efficiency of the selfconsistent method is largely linked to the definition of the reference space used for characterizing the errors, considering for instance instrument geometry relative to orbit passes, to 

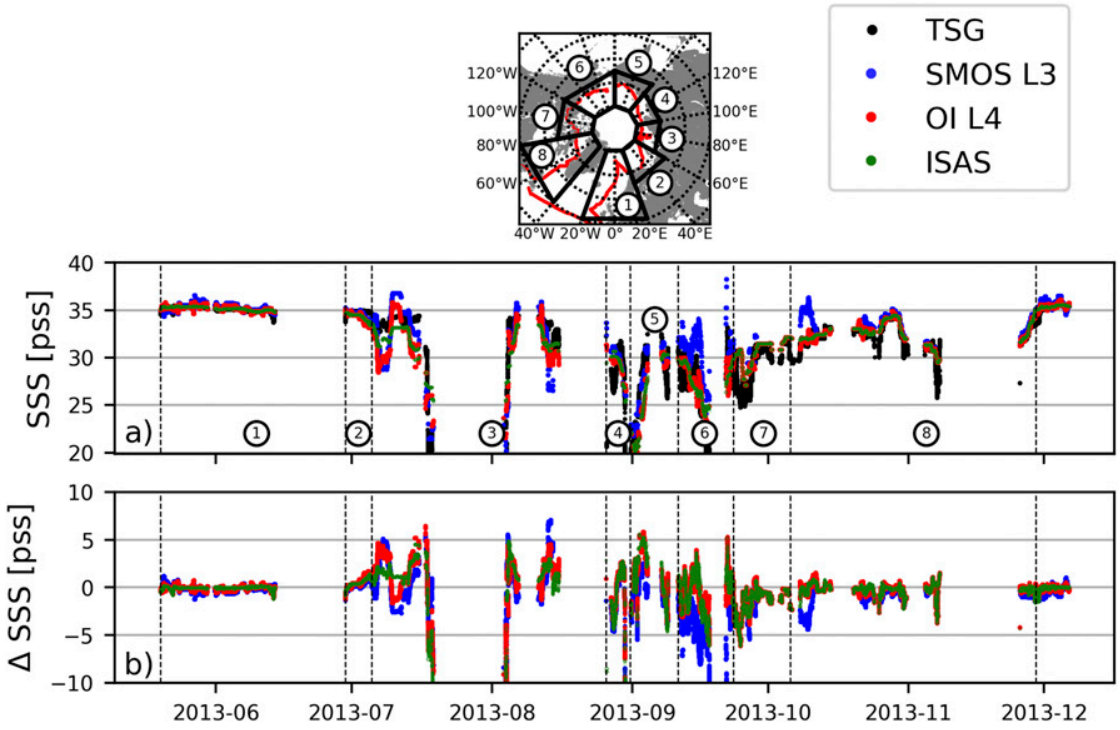

FIG. 12. (a) Comparison and (b) SSS differences between collocated Tara TSG SSS (black) and OI L4 SSS (red), SMOS SSS (blue) and ISAS (green) during Tara cruises between May 2013 and December 2013 over the Arctic Ocean. Codes used are $1=$ Nordic seas, $2=$ Barents Sea, $3=$ Kara Sea, $4=$ Laptev Sea, $5=$ eastern Siberian Seas, $6=$ Beaufort Gyre, $7=$ Northwest Passage, and $8=$ Baffin Bay and Labrador Sea.

coastline, to sun and seasonal related effects. No absolute correction is introduced by in situ data such as in situ SSS interpolated field at weekly or monthly time scales, so as to preserve as much as possible the SSS variability sampled by the satellite data and not to relax to a climatology in regions/periods when no in situ measurement is available, at the expense of possible remaining large-scale errors and remaining time-varying bias in the mid- to high latitudes (see Figs. 3 and 6 at http://cci.esa.int/sites/default/files/SSS_cciD4.1-PVIR-v1.1-signed.pdf).

From the subtropical to subpolar latitudes, the present procedure significantly reduces the large-scale and time-varying bias in comparison to L3 SSS products. This approach has been demonstrated for correcting SMOS SSS alone in order to estimate the contribution of the eddy advection to the seasonal and interannual SSS budget in the North Atlantic subtropical SSS maximum (Sommer et al. 2015). However, at higher latitudes the small eddy scales (Chelton et al. 1998) hinders proper mapping of the major SSS eddy features with SMOS and SMAP resolution, advocating for higher resolution satellite observation of SSS.

The method is efficient in regions that are sufficiently sampled by the Argo network, which provides accurate estimates of the large-scale SSS pattern. In contrast, in regions that are poorly sampled by the Argo array, that is, in the Arctic Ocean, coastal regions and marginal ice zone, ISAS uses a background WOA monthly climatology. Thus, reference large-scale SSS fields are less reliable in these regions. Yet, despite higher frequency coverage due to circular orbits of SMOS and SMAP in the polar ocean, low SST and sea ice margins still result in large errors in L-band radiometer SSS retrievals. Therefore, the large-scale correction and merging of SMOS/SMAP data still results in an improved signal-to-noise ratio of satellite SSS field with respect to ISAS and L3 SSS products.

A remaining challenging issue is filtering the SSS from sea ice contamination that introduces biases in the vicinity of the ice marginal zone and the moving "coastal-like" contamination that results from the seasonal migration of the sea ice edges. The SMOS ice mask applied on the SMOS L3 products used in this study was derived from the SMOS retrieved pseudo dielectric constant similar to what is used in Supply et al. (2020) but using an earlier version of the processing with a more permissive threshold. It is thus expected that sea ice filtering could be improved in future SMOS L3. Olmedo et al. (2018) have proposed a alternative method based on a correction of the SMOS SSS at the L2 level using WOA. They produce relatively accurate SSS field in the Arctic ocean; however, they use a smoothing procedure with a large horizontal scale that does not take advantage of the SMOS resolution capability. Furthermore, as they use WOA monthly climatology, this provides less accurate instantaneous corrections in regions poorly sampled by the in situ network, such as the Arctic Ocean. In this region, the major role played by the freshwater flux and salinity for the ocean dynamics and the lack of in situ data provides a high potential for SSS remote sensing. Furthermore, SMOS SSS has proven to be relevant for observing strong SSS contrasts in large Arctic river plumes (Matsuoka et al. 2016; Tarasenko et al. 2021; Supply et al. 2020). These methods for correcting L-band SSS and future satellite missions will provide new opportunities to investigate ocean freshwater and climate variability at high latitude.

Acknowledgments. This study was supported by the CNES CATDS and CNES TSOSCA SMOS OCEAN project. 
Author M. Hamon was supported by CNES CATDS and ESA funding; A. Supply was supported by an SU Ph.D. grant.

Data availability statement. The SMOS/SMAP OI L4 SSS maps over the period 2011-2018 (this study) are freely distributed on demand (https://doi.org/10.17882/73142). The ISAS-15 data (https://doi.org/10.17882/52367) are freely available. The ISAS-NRT product is available from the Copernicus Marine Service (https://resources.marine.copernicus.eu/?option= com_csw\&view=details\&product_id=INSITU_GLO_TS_OA_ NRT_OBSERVATIONS_013_002_a). SMOS CEC L3 debias v3 SSS data are freely available (https://doi.org/10.17882/52804). SMAP RSS L3 v3 SSS data and AMSR-E/2 SST data are produced by Remote Sensing Systems. They are sponsored by NASA Ocean Salinity Science Team and by the NASA AMSR-E/2 Science Team and the NASA Earth Science MEaSUREs Program, respectively, and are freely available (http://www.remss.com). ODYSSEA SST products are freely available (http://products.cersat.fr/). TSG SSS and SST data from research vessel are freely available (https://doi.org/10.17882/ 39475). TSG SSS and SST from merchant ships are freely available via SNO-SSS at LEGOS (http://www.legos.obs-mip.fr/ observations/sss).

\section{REFERENCES}

Alory, G., and Coauthors, 2015: The French contribution to the voluntary observing ships network of sea surface salinity. Deep-Sea Res. I, 105, 1-18, https://doi.org/10.1016/j.dsr. 2015.08.005.

Autret, E., J. F. Piollé, and C. Prévost, 2019, Quality information document for high resolution global ocean sea surface temperature L3 observations. Copernicus Doc., 17 pp., http:// resources.marine.copernicus.eu/documents/QUID/CMEMSSST-QUID-010-010.pdf.

Björk, G., 2017: CTD data from the SWERUS-C3 expedition 2014 in the Arctic Ocean. PANGAEA, accessed 31 December 2019, https://doi.org/10.1594/PANGAEA.884144.

Boutin, J., and Coauthors, 2016: Satellite and in situ salinity: understanding near-surface stratification and subfootprint variability. Bull. Amer. Meteor. Soc., 97, 1391-1407, https:// doi.org/10.1175/BAMS-D-15-00032.1.

__ , and Coauthors, 2018a: New SMOS sea surface salinity with reduced systematic errors and improved variability. Remote Sens. Environ., 214, 115-134, https://doi.org/10.1016/j.rse.2018.05.022.

—_, J.-L. Vergely, C. Thouvenin-Masson, A. Supply, and D. Khvorostyanov, 2018b: SMOS SSS L3 maps generated by CATDS CEC LOCEAN, debias V3.0. SEANO, accessed 19 July 2019, https://doi.org/10.17882/52804\#57467.

,-- J. Koehler, F. Rouffi, N. Reul, 2019: ESA sea surface salinity climate change initiative (Sea_Surface_Salinity_cci), version 1.8 data collection. Centre for Environmental Data Analysis, accessed 25 November 2019, https://doi.org/10.5285/ 9ef0ebf847564c2eabe62cac4899ec41.

Bretherton, F., R. Davis, and C. Fandry, 1976: Technique for objective analysis and design of oceanographic experiment applied to MODE-73. Deep-Sea Res. Oceanogr. Abstr., 23, 559-582, https://doi.org/10.1016/0011-7471(76)90001-2.

Buongiorno Nardelli, B., 2012: A novel approach for the highresolution interpolation of in situ sea surface salinity. J. Atmos. Oceanic Technol., 29, 867-879, https://doi.org/10.1175/JTECHD-11-00099.1.
_, R. Droghei, and R. Santoleri, 2016: Multi-dimensional interpolation of SMOS sea surface salinity with surface temperature and in situ salinity data. Remote Sens. Environ., 180, 392-402, https://doi.org/10.1016/j.rse.2015.12.052.

Carmack, E., 2007: The alpha/beta ocean distinction: A perspective on freshwater fluxes, convection, nutrients and productivity in high-latitude seas. Deep-Sea Res. II, 54, 2578-2598, https:// doi.org/10.1016/j.dsr2.2007.08.018.

Chelton, D. B., R. A. deSzoeke, M. G. Schlax, K. El Naggar and N. Siwertz, 1998: Geographical variability of the first baroclinic Rossby radius of deformation. J. Phys. Oceanogr., 28, 433-460, https://doi.org/10.1175/1520-0485(1998)028<0433: GVOTFB $>2.0 . \mathrm{CO} ; 2$.

Dewey, S. R., J. H. Morisin, and J. Zhang, 2017: An edge-reference surface fresh layer in the Beaufort Sea seasonal ice zone. J. Phys. Oceanogr., 47, 1125-1144, https://doi.org/10.1175/ JPO-D-16-0158.1.

Droghei, R., B. Buongiorno Nardelli, and R. Santoleri, 2016: Combining in situ and satellite observations to retrieve salinity and density at the ocean surface. J. Atmos. Oceanic Technol., 33, 1211-1223, https://doi.org/10.1175/JTECH-D-15-0194.1.

Durack, P. J., S. E. Wijffels, and R. J. Matear, 2012: Ocean salinities reveal strong global water cycle intensification during 1950 to 2000. Science, 336, 455-458, https://doi.org/10.1126/ science. 1212222

Durand, F., G. Alory, R. Dussin, and N. Reul, 2013: SMOS reveals the signature of Indian Ocean dipole events. Ocean Dyn., 63, 1203-1212, https://doi.org/10.1007/s10236-013-0660-y.

Flament, P., 2002: A state variable for characterizing water masses and their diffusive stability: Spiciness. Prog. Oceanogr., 54, 493-501, https://doi.org/10.1016/S0079-6611(02) 00065-4.

Font, J., and Coauthors, 2010: SMOS: The challenging sea surface salinity measurement from space. Proc. IEEE, 98, 649-665, https://doi.org/10.1109/JPROC.2009.2033096.

Fournier, S., B. Chapron, J. Salisbury, D. Vandemark, and N. Reul, 2015: Comparison of space borne measurements of sea surface salinity and colored detrital matter in the Amazon plume. J. Geophys. Res. Oceans, 120, 3177-3192, https://doi.org/ 10.1002/2014JC010109.

_ J. Jialard, M. Lengaigne, T. Lee, M. M. Gierach, and A. V. S. Chaitanya, 2017: Modulation of the Ganges-Brahmaputra River plume by the Indian Ocean dipole and eddies inferred from satellite observations. J. Geophys. Res. Oceans, 122, 9591-9604, https://doi.org/10.1002/2017JC013333.

Gaillard, F., T. Reynaud, V. Thierry, N. Kolodziejczyk, and K. von Schuckmann, 2016: In situ-based reanalysis of the global ocean temperature and salinity with ISAS: Variability of the heat content and steric height. J. Climate, 29, 1305-1323, https://doi.org/10.1175/JCLI-D-15-0028.1.

Hackert, E., and Coauthors, 2020: Satellite sea surface salinity observations impact on El Niño/Southern Oscillation predictions: Case studies from the NASA GEOS seasonal forecast system, J. Geophys. Res. Oceans, 125, e2019JC015788, https:// doi.org/10.1029/2019JC015788.

Hasson, A., T. Delcroix, J. Boutin, R. Dussin, and J. BallabreraPoy, 2014: Analyzing the 2010-2011 La Niña signature in the tropical Pacific sea surface salinity using in situ data, SMOS observations, and a numerical simulation. J. Geophys. Res. Oceans, 119, 3855-3867, https://doi.org/10.1002/2013JC009388. , M. Puy, J. Boutin, E. Guilyardi, and R. Morrow, 2018: Northward propagation across the tropical North Pacific Ocean revealed by surface salinity: How do El Niño anomalies 
reach Hawaii? J. Geophys. Res. Atmos., 123, 2697-2715, https://doi.org/10.1002/2017JC013423.

— - J. T. Farrar, J. Boutin, F. Bingham, and T. Lee, 2019: Intraseasonal variability of surface salinity in the eastern tropical Pacific associated with mesoscale eddies. J. Geophys. Res. Oceans, 124, 2861-2875, https://doi.org/10.1029/ 2018JC014175.

Huang, R., 2011: Defining the spicity. J. Mar. Res., 69, 545-559, https://doi.org/10.1357/002224011799849390.

Ide, K., P. Courtier, M. Ghil, and A. C. Lorenc, 1997: Unified notation for data assimilation: Operational, sequential and variational. J. Meteor. Soc. Japan, 75, 181-189, https://doi.org/ 10.2151/jmsj1965.75.1B_181.

IOC, SCOR, and IAPSO, 2010: The International Thermodynamic Equation of Seawater-2010: Calculation and use of thermodynamic properties. Intergovernmental Oceanographic Commission, Manuals and Guides 56, 220 pp., http://www.teos10.org/pubs/TEOS-10_Manual.pdf.

Kerr, Y. H., and Coauthors, 2010: The SMOS mission: New tool for monitoring key elements of the global water cycle. Proc. IEEE, 98, 666-687, https://doi.org/10.1109/JPROC. 2010.2043032.

Kolodziejczyk, N., G. Reverdin, J. Boutin, and O. Hernandez, 2015a: Observation of the surface horizontal thermohaline variability at mesoscale to submesoscale in the north-eastern subtropical Atlantic Ocean. J. Geophys. Res. Oceans, 120, 2588-2600, https://doi.org/10.1002/2014JC010455.

— O. Hernandez, J. Boutin, and G. Reverdin, 2015b: SMOS salinity in the subtropical North Atlantic salinity maximum: 2. Two-dimensional horizontal thermohaline variability. J. Geophys. Res. Oceans, 120, 972-987, https://doi.org/10.1002/ 2014JC010103.

—, J. Boutin, J. L. Vergely, S. Marchand, N. Martin, and G. Reverdin, 2016: Mitigation of systematic errors in SMOS sea surface salinity. Remote Sens. Environ., 180, 164-177, https://doi.org/10.1016/j.rse.2016.02.061.

— A. Arigent-Mazella, and F. Gaillard, 2017: ISAS-15 temperature and salinity gridded fields. SEANO, accessed 31 December 2017, https://doi.org/10.17882/52367.

Lagerloef, G., 2012: Satellite mission monitors ocean surface salinity. Eos, Trans. Amer. Geophys. Union, 93, 233-234, https:// doi.org/10.1029/2012EO250001.

— to meet the salinity remote sensing challenge. Oceanography, 21 (1), 68-81, https://doi.org/10.5670/oceanog.2008.68.

Lee, T., G. Lagerloef, M. M. Gierach, H.-Y. Kao, S. Yueh, and K. Dohan, 2012: Aquarius reveals salinity structure of tropical instability waves. Geophys. Res. Lett., 39, L12610, https://doi.org/ 10.1029/2012GL052232.

Lique, C., 2015: Arctic sea ice heated from below. Nat. Geosci., 8, 172-173, https://doi.org/10.1038/ngeo2357.

Lukas, R., and E. Lindstrom, 1991: The mixed layer of the western equatorial Pacific Ocean. J. Geophys. Res., 96, 3343-3357, https://doi.org/10.1029/90JC01951.

Makhotin, M., and V. Ivanov, 2018: Physical oceanography measured with CTD/Watersampler-system during PU2014 to the Barents Sea in 2014. PANGAE, accessed 31 December 2019, https://doi.org/10.1594/PANGAEA.895271.

Matsuoka, A., M. Babin, and E. C. Devred, 2016: A new algorithm for discriminating water sources from space: A case study for the southern Beaufort Sea using MODIS ocean color and SMOS salinity data. Remote Sens. Environ., 184, 124-138, https://doi.org/10.1016/j.rse.2016.05.006.
McDougall, T. J., and O. A. Krzysik, 2015: Spiciness. J. Mar. Res., 73, 141-152, https://doi.org/10.1357/002224015816665589.

Meissner, T., F. J. Wentz, J. Scott, and J. Vasquez-Cuervo, 2016: Sensitivity of ocean surface salinity measurements from spaceborne L-band radiometers to ancillary sea surface temperature. IEEE Trans. Geosci. Remote Sens., 54, 71057111, https://doi.org/10.1109/TGRS.2016.2596100.

,-- , and D. M. Le Vine, 2018: The salinity retrieval algorithms for the NASA Aquarius version 5 and SMAP version 3 releases. Remote Sens., 10, 1121, https://doi.org/10.3390/ rs10071121.

,,-- A. Manaster, and R. Lindsley, 2019: NASA/RSS SMAP salinity: Version 4.0 validated release. Release notes algorithm. Remote Sensing Systems Tech. Rep. 082219, 55 pp.

Melnichenko, O., P. Hacker, N. Maximenko, G. Lagerloef, and J. Potemra, 2014: Spatial optimal interpolation of Aquarius sea surface salinity: Algorithms and implementation in the North Atlantic. J. Atmos. Oceanic Technol., 31, 1583-1600, https://doi.org/10.1175/JTECH-D-13-00241.1.

Olmedo, E., and Coauthors, 2018: Seven years of SMOS sea surface salinity at high latitudes: Variability in Arctic and subArctic regions. Remote Sens., 10, 1772, https://doi.org/10.3390/ rs10111772.

Picaut, J., M. Ioualalen, T. Delcroix, F. Masia, R. Murtugudde, and J. Vialard, 2001: The oceanic zone of convergence on the eastern edge of the Pacific warm pool: A synthesis of results and implications for El Niño-Southern Oscillation and biogeochemical phenomena. J. Geophys. Res., 106, 2363-2386, https://doi.org/10.1029/2000JC900141.

Piepmeier, J. R., and Coauthors, 2017: SMAP L-band microwave radiometer: Instrument design and first year on orbit. IEEE Trans. Geosci. Remote Sens., 55, 1954-1966, https://doi.org/ 10.1109/TGRS.2016.2631978.

Portela, E., N. Kolodziejczyk, C. Maes, and V. Thierry, 2020: Interior water-mass variability in the Southern Hemisphere oceans during the last decade. J. Phys. Oceanogr., 50, 361-381, https://doi.org/10.1175/JPO-D-19-0128.1.

Reul, N., and Coauthors, 2014a: Sea surface salinity observations from space with the SMOS satellite: A new means to monitor the marine branch of the water cycle. Surv. Geophys., 35, 681722, https://doi.org/10.1007/s10712-013-9244-0.

—-, Chapron, B., Lee, T., Donlon, C., Boutin, J., Alory, G., 2014b: Sea surface salinity structure of the meandering Gulf Stream revealed by SMOS sensor. Geophys. Res. Lett., 41, 3141-3148, https://doi.org/10.1002/2014GL059215.

_ , and Coauthors, 2020: Sea surface salinity estimates from spaceborne L-band radiometers: An overview of the first decade of observation (2010-2019). Remote Sens. Environ., 242, 111769, https://doi.org/10.1016/j.rse.2020.111769.

Reynaud, T., N. Kolodziejczyk, C. Maes, F. Gaillard, G. Reverdin, F. D. de Gesincourt, and H. Le Goff, 2015: Sea surface salinity from sailing ships: Delayed mode dataset, annual release. SEANOE, accessed 31 December 2018, https://doi.org/10.17882/ 39476.

Reynolds, R. W., and T. M. Smith, 1994: Improved global sea surface temperature analyses using optimal interpolation. J. Climate, 7, 929-948, https://doi.org/10.1175/1520-0442(1994) 007<0929:IGSSTA > 2.0.CO;2.

Riser, S. C., and Coauthors, 2016: Fifteen years of ocean observations with the global Argo array. Nat. Climate Change, 6, 145153, https://doi.org/10.1038/NCLIMATE2872.

Roemmeich, D., and Coauthors, 2019: On the future of Argo: An enhanced global array of physical and biogeochemical 
sensing floats. Front. Mar. Sci., 6, 439, https://doi.org/10.3389/ fmars.2019.00439.

Shenoi, S. S. C., Shankar, D., 2002. Differences in heat budgets of the near-surface Arabian Sea and Bay of Bengal: Implications for the summer monsoon. J. Geophys. Res., 107, 3052, https:// doi.org/10.1029/2000JC000679.

Sommer, A., G. Reverdin, N. Kolodziejczyk, and J. Boutin, 2015: Sea surface salinity and temperature budgets in the North Atlantic Subtropical Gyre during SPURS Experiment: August 2012-August 2013. Front. Mar. Sci., 2, 107, https://doi.org/ 10.3389/fmars.2015.00107.

Stewart, K. D., T. W. N. Haine, A. M. Hogg, and F. Roquet, 2017: On cabbeling and thermobaricity in the surface mixed layer. J. Phys. Oceanogr., 47, 1775-1787, https://doi.org/10.1175/ JPO-D-17-0025.1.

Supply, A., J. Boutin, J.-L. Vergely, N. Kolodziejczyk, G. Reverdin, N. Reul, and A. Tarasenko, 2020: A new methodology to derive SMOS sea surface salinity in the Arctic Ocean. Remote Sens. Environ., 249, 112027, https://doi.org/10.1016/ j.rse.2020.112027.

Tang, W., S. Yueh, D. Yang, A. Fore, A. Hayashi, T. Lee, S. Fournier, and B. Holt, 2018: The potential and challenges of using Soil Moisture Active Passive (SMAP) sea surface salinity to monitor Arctic Ocean freshwater changes. Remote Sens., 10, 869, https://doi.org/10.3390/rs10060869.

Tarasenko, A., and Coauthors, 2021: Properties of surface water masses in the Laptev and the East Siberian seas in summer
2018 from in situ and satellite data. Ocean Sci., 17, 221-247, https://doi.org/10.5194/os-17-221-2021.

Thomas, L., and C. J. Shakespeare, 2015: A new mechanism for mode water formation involving cabbeling and frontogenetic strain at thermohaline fronts. J. Phys. Oceanogr., 45, 24442456, https://doi.org/10.1175/JPO-D-15-0007.1.

Vialard, J., and P. Delecluse, 1998: An OGCM study for the TOGA decade. Part I: Role of salinity in the physics of the western Pacific fresh pool. J. Phys. Oceanogr., 28, 1071-1088, https:// doi.org/10.1175/1520-0485(1998)028<1071:AOSFTT>2.0.CO;2.

Vinogradova, N., and Coauthors, 2019: Satellite salinity observing system: Recent discoveries and the way forward. Front. Mar. Sci., 6, 243, https://doi.org/10.3389/fmars.2019.00243.

Wentz, F. J., T. Meissner, C. Gentemann, K. A. Hilburn, and J. Scott, 2014: Remote sensing systems GCOM-W1 AMSR2 weekly, environmental suite on $0.25 \mathrm{deg}$ grid, version V.8.1. Remote Sensing Systems, accessed 15 March 2019, www.remss.com/ missions/amsr.

Xie, J., R. P. Raj, L. Bertino, A. Samuelsen, and T. Wakamatsu, 2019: Evaluation of Arctic Ocean surface salinities from the Soil Moisture and Ocean Salinity (SMOS) mission against a regional reanalysis and in situ data. Ocean Sci., 15, 1191-1206, https://doi.org/10.5194/os-15-1191-2019.

Yin, X., J. Boutin, G. Reverdin, T. Lee, S. Arnault, and N. Martin, 2014: SMOS sea surface salinity signals of tropical instability waves. J. Geophys. Res. Oceans, 119, 7811-7826, https://doi.org/ 10.1002/2014JC009960. 